\title{
Index for Volume 99
}

AUTHOR AND SUBJECT INDEX. Pages indicating errata are in italic. "A" indicates abstract. Author index for supplement issue is at the end.

Abad, G., 792

Abbasi, P. A., 274

Abou Haider, C., A111

Abstracts, special session presentations, S152

Aceria mangifera on mango: Fusarium interaction, 152; symptoms, cover photo, February Acidovorax spp.

-A. avenae: on cucurbits, Didymella bryoniae infection, 666; on cucurbits, evolutionary lineages, 913; on melon and watermelon seed, survival, S119; on watermelon, seed detection assay, S198; on watermelon, types II and III secretion, S59

-A. citrulli, on cucurbit, seed detection, S143

Acremonium zeae, on maize, pyrrocidines, antimicrobial, 109

Actinomyces, biocontrol strain, antiviral metabolite, $\mathrm{S} 105$

Aegerter, B. J., 67

Aegilops tauschii, stem rust, resistance, S111

Afunian, M. R., 423

Agrobacterium tumefaciens

-Cochliobolus sativus transformation, S70

- polar attachment, S154

—on walnut, seed-borne populations, S145

Aikawa, T., 1365

Ajab, M., 1265

Akimitsu, K., 369

Alary, R., 265, 632

Alfalfa, pathogens and lignins, S132

Allen, C., 1127

Allium spp. (see also Onion)

-Penicillium decay, resistance, S30

Allium virus $X$, on allium, characterization, $\mathrm{S} 85$

Alma, A., 711

Almond

-anthracnose, characterization in Australia, 985

—brown line, etiology in California, S126

Alternanthera mosaic virus, Gene Block Protein, S73

Alternaria spp., chromosomes, sequencing, S55; mating locus, codon usage, $\mathrm{S} 124$

$-A$. alternata, on citrus, strobilurin resistance, S88; on pistachio, boscalid sensitivity, S6; on tangerine, diversity in Iran, S60; on tangerine, host-selective toxin, 369

-A. solani, molecular diversity, Brazil, 765

Alvarado, V., 3

Aly, R., 1321

Amaranthus tricolor, leaf blight, endophytes in management, S201

Ambrósio, S., 307

Ambrosia trifida, marafvirus, ring spot, S112

American Phytopathological Society

- annual report, 17

-Distinguished Service Award, 19

-Extension, Excellence Award, 29

-fellows, 20

- Hewitt Award, 35

-Industry, 30

-International Scientific Society on Plant Health abstracts, $\mathrm{S} 188$

-International Service Award, 32

-Melhus Graduate Student Symposium, S158

-Noel T. Keen Award, 33

-Northeastern Division meeting abstracts 2008, S191

—officers, representatives, committees, 14

-Pacific Division abstracts, 2008, S180

-Potomac Division meeting abstracts 2009, S203

-Ruth Allen Award, 34

- Southern Division meeting abstracts 2009, S196

-Syngenta Award, 36

-Teaching, 31
Amiri, A., 1199

Ampelomyces quisqualis, powdery mildew parasite, 704

Amplovirus, grape hosts, vectors, 1177

Angeli, D., 704

Antibiotics, 2,4-diacetylphloroglucinol: Gaeumannomyces graminis, 472; Pseudomonas fluorescens, seed treatment, 506

Antrodia sinuosa, on lemon, rootstock effect, S184

Aoun, M., 642

Aphanomyces euteiches

—on alfalfa, races 1 and 2, S43

-Medicago truncatula, resistance gene, 203

Aphelenchus avenae, feeding on Phytophthora and Pythium spp., S41

Aphis gossypii, Citrus tristeza virus vector, variance, 1168

Apple (see also Malus sieversii)

-bacterial pathogens, microarray analysis, S14

-blue mold rot: fludioxonil and pyrimethanil, S187; postharvest biological control, 258

-Cacopaylla melanoneura, nonvector, 729

- disease resistance, cisgenic approach, S42

-disease resistance transformation, strategy, S191

-fire blight: bacteria and yeasts as antagonists, 571; biological control, 128; kasugamycin for control, S82; resistance induced by prohexadione-calcium, 591

-fungicides, management in Vermont, S26

-integrated pest management, eco-label program, S191

-Penicillium solitum, decay and polygalacturonase, 636

-plastoglobule osmiophilicity, sensitivity, S120

- postharvest diseases, biocontrol, S159

— scab and powdery mildew, new fungicide, S41

- sooty blotch and flyspeck, phosphite fungicides, S195

Arabidopsis

—cyst nematode, peptides, S108

- transgenic, stress response, $\mathrm{S} 144$

Arabidopsis thaliana

-flagellin receptor, structure-function analysis, S126

-Geminivirus C4 transgene, deprogramming, S86

Arai, K., 209

Arauz, L. F., 620

Armillaria spp.: on blueberry, genetic diversity in Italy, 651; climate change effect, predicting, S65

-A. mellea, population structure, California, S9

Arneodo, J., 1289

Arsenophonus. vector transmission and ecological traits, endosymbionts, 1289

Ascochyta rabiei, on chickpea, pathogenicity determinants, S141

Ascophyllum nodosum, on Arabidopsis, resistance induced, S125

Asea, G., 540

Aspergillus spp.: aflatoxin diversity, world population, S88; on almond, aflatoxin, humidity effect, S77; on almond, aflatoxins, S85

-A. flavus: A. oryzae comparison, genomes, S42; aflatoxin, application time, S58; aflatoxin, biocontrol, S27; on corn, aflatoxigenicity, S126; on corn, isolate interaction, S82; genotypic diversity, aflatoxins, S47; on peanut, detection, S201; toxigenic isolate competition, S1; VeA and LaeA roles, S159

-A. nedulans: DNA damage checkpoint pathway, antagonism, S203; genotoxic stress, mutants, S204
-A. ochraceus, ochratoxin A biosynthesis, S31

Atallah, Z. K., 1008

Athinuwat, D., 996

Aura, J. M., 519

Aureobasidium microstictum, on daylily, incidence, S71

Austerweil, M., 362

Austin, G. D., 957

Author index abstracts, S206

Auxin, indole-3-acetic acid, biocontrol, apple blue mold, 258

Avis, T. J., 167

Avocado, laurel wilt, recovery plan, S102

Azalea, Rhizoctonia web blight, containers, S24

Bacetty, A. A., 1336

Bacillus spp.: on cacao, pod diseases, S83; metabolites for biocontrol, S150; on oilseed rape, stem rot control, S39

-B. amyloliquefaciens, fermentation, S140

-B. mojavensis, surfactin production, $\mathrm{S} 7$

-B. mycoides, on pecan, biocontrol, S196

-B. subtilis, antibiotic, rhizosphere, S193

Bacon, C. W., 1336

Bacteria

—biofilm inhibitor-dispersant, bromoageliferin, S108

-chaperones, type III secretion, S130

- ecology, plants, S155

—enteric, evolution, S167

- genomes, comparative analysis, S115

-Gram negative, mutation detection, S28

-macroarray, role, S97

Bagnoli, B., 711

Bailey, D. J., 861

Bakker, J., 194, 227

Bakker, P. A. H. M., 472

Banana

-Black Sigatoka, bio-fungicide, S80

-Fusarium wilt, silicon, S36

-fuzzy pedicel, new disease, $\mathrm{S} 127$

Banana bunchy top virus

— coat protein-based genealogy, Africa, S68

-strain evolution, 812

Bancal, M.-O., 1216

Bandyopadhyay, R., 353

Baranger, A., 203

Bardin, M., 185

Barley

-deoxynivalenol, ethanol co-products, S204

-Rhizoctonia root rot, glyphosate timing, S6

-root rot, resistance mapping, S49

-Sclerotinia blight, resistance gene, S55

-soybean rust, transgenic suppression, cell death, 220

—stem rust: race TTKSK, resistance, 1135; races in Washington, S111; resistance from Hordeum bulbosum, 339

-swathing and combining, Fusarium head blight control, S47

Barley yellow dwarf virus, vector survey in Alabama and Florida, S49

Barnes, C. W., 328

Barquero, M. P., 620

Basu, D., 1245

Bau, H.-J., 1312

Bauhinia spp., Phyllachora "tar spots", Brazil, S98

Beales, P., 792

Bean pod mottle virus

-population in Mississippi, S124

-risk factors, Iowa, S18

Bean, S. R., S94

Bean yellow mosaic virus 
-Clover yellow vein virus cross-protection, 251

-host specialization, recombination, 512

Beet black scorch virus, diversity in Iran, S84

Beet curly top virus

- bean and sugar beet, immunodetection, S30

—on cucurbit, leafhopper transmission, 101

Beet mild curly top virus, on cucurbit, leafhopper transmission, 101

Beet necrotic yellow vein virus, epidemiology, $\mathrm{S} 1$

Beet severe curly top virus, tissue tropism, S22

Beet yellows virus, systemic spread, aphids, S103

Begomovirus, whitefly interaction, S153

Bélanger, R. R., 1142

Belausov, E., 152

Belzile, F., 1142

Berger, P. H., 390

Bernal, A. J., 82

Bernardes-de-Assis, J., 1090

Berner, D. K., 1045

Bernier, L., 642

Bertolini, E., 301

Beta vulgaris (see also Sugar beet)

-damping-off, S92

-powdery mildew, resistance mechanisms, 385

Bi, C. W., 1403

Bigirwa, G., 540

Bilodeau, G. J., 390, 792

Biological control

-Acremonium zeae for maize pathogens, 109

- bacteria and yeasts to Erwinia amylovora, on apple, 571

-bacterial and fungal interactions, S129

-bacterial strains, potential, S54

-biopesticide regulation, EPA, S175

—broad spectrum bio-fungicide, S134

- control agents, selection, S174

-Cryptocccus laurentii for apple blue mold, 258

-fire blight of apple and pear, 128

-Fusarium head blight on wheat and barley, Bacillus strain, $\mathrm{S} 12$

-Fusarium spp., S175

-microbe application ri sk, S175

-pathogens for weeds, risks, S175

-Pseudomonas fluorescens: 2,4-diacetylphloroglucinol production, seed treatment, 506; RpoS role, tolerance and fitness, 689; stress and environment, 679

-Pseudozyma flocculosa, genes, 1142

-sclerotial colonization, PCR and microscopy, S64

-Snakin-1 and Defensin-1 activity, Clavibacter and Colletotrichum spp., S67

Biosecurity, agricultural, decision tool, S110

Biosensor, CANARY, pathogen detection, S75

Bipolaris oryzae

-on rice, silicon uptake, 116

—variability, Philippines, S17

Blackberry

-flexivirus, nucleotide sequence, S112

- viruses, Alabama, S24

Blomquist, C. (Md.), 390

Blomquist, C. L. (Calif.), 792

Blueberry scorch virus, nursery stock, S98

Blumeria graminus

-on wheat: genetic analysis, UK and Israel, 840; geostatistical analysis, 974; resistance and quantitative trait loci, 1121

Bonants, P. J. M., 792

Bondalapati, K. D., 759

Bone, K. R., 176

Bostock, R. M., 1307

Botryosphaeria spp.: on apple and pear, canker and ring rot comparison, $\mathrm{S} 48$; on avocado, California, S81; on blueberry, Florida, S143; on tree nut crops, continent survey, S56

-B. obtusa, on apple, fruit thinning effect, New York, S111

Botryosphaeriaceae, on trees, South Africa, 121

Botrytis spp.
-B. cinerea: on apple, pyraclostrobin and boscalid resistance, S63; on apple and pear, fungicide sensitivity, S150; on blueberry, biocontrol, $\mathrm{S} 121$; on flowers, resistance induced, S128; on grape: chitosan for control, 1028; on grape, post-harvest control, S134; on lisianthus, factors and management, 557; necrosis role, S63; on Rosa spp., fungicide sensitivity, S40; on strawberry, fungicide resistance, $\mathrm{S} 84$; on tomato, genetic diversity in glasshouse, 185

-B. squamosa, on onion, airborne conidia, PCR assay, 1273

Boucher, C., 1105

Boudon-Padieu, E., 1289

Bowersox, V. C., 328

Bradysia impatiens, on geranium, mechanical wounding effect, 1421

Brasier, C., 792

Brassica napus (see also Canola)

- fungal diseases, Turkey, S62

-Verticillium longisporum, resistance, cover photo, July

-Verticillium wilt, resistance and systemic spread, 802

Brassicaceae, Meloidogyne and Pratylenchus spp., seed meals for control, S148

Braun, S. E., 1421

Brenneria rubrifaciens, on walnut, rubifacine production, genetics, 145

Bressan, A., 1289

Brière, S. C., 792

Brlansky, R. H., 1297

Broders, K. D., 957

Brown, C. R., 1085

Brown-Guedira, G., 320

Browning, M., 1045

Brueggeman, R. S., 1135

Bugiani, R., 453

Burkholderia spp.

-B. cepacia, characterization, S30

-B. contaminans: occidiofungin, gene cluster, S76; occidiofungin production, genetics, S47

-B. glumae, avirulent strains, S62

-B. pyrrocinia: biocontrol, S136; on geranium, foliar biofilms, S136

Burns, J. K., 50

Burr, T., 996

Bursaphelenchus xylophilus, on pine, using isothermal amplification, 1365

Butterbach, P., 194

Cacao, Bacillus for biocontrol, S83

Cacopaylla melanoneura, on apple, nonvector, 729

Cadle-Davidson, L., S89

Calibrachoa mottle virus, nucleotide sequence and genome, S114

Calonnec, A., 411

Cambra, M., 301

Camellia spp., trig blight, model, 378

-C. sinensis, bacterial shoot blight, environmental control, 209: genetic diversity, S15; genetic diversity, Asia, 1062; huanglongbing association, 480

'Candidatus Liberibacter sp.: on potato, zebra chip, S140; taxonomy, DNA sequencing, S115

- 'Candidatus Liberibacter americanus', on citrus: huanglongbing association, 480; transmission efficiency, 301

- 'Candidatus Liberibacter asiaticus': on citrus, detection markers, S74; on citrus, distribution, 139; on citrus, seed transmission, S11; on citrus, transmission efficiency, 301; genetic diversity, S15; genetic diversity, Asia, 1062; genetic diversity, Florida, S116; huanglongbing association, 480; on sweet orange, analyses, 50

- 'Candidatus Liberibacter asteri', on citrus, China, 236

- 'Candidatus Liberibacter solanacearum', on potato, genome, S73

-'Candidatus Phytoplasma prunorum', on

Prunus spp., transmission efficiency, 265, 632

- 'Candidatus Phytoplasma solani': on maize,

Reptalus panzeri transmission, 1053; stolbur

disease, isolate characterization, 711

Canna indica, badnavirus, variability, S113

Canola (see also Brassica napus)

-Phoma stem canker, rainfall and temperature model, 879

-Sclerotinia stem rot: biocontrol, S79; rotation and fungicides, S58;

— seedling blight, seed factors, S56

Cantaloupe (see also Melon)

- curly top symptoms, leafhopper tramsmission, cover photo, January

Capsicum spp.

-C. annuum: endornavirus, host range and signaling, S134; potyvirus resistance, S91; Pythium myriotylum, cross-flow membrane filtration, hydroponics, 597; viruses, Mexico, S45

-C. baccatum, anthracnose, resistance genes, 1100

Carbone, I., 765, 840

Career

-agricultural consultant, S177

-field scientist, S177

-industry, myths, S176

-industry development, S177

— job skills, S176

_Public Policy Board intern, reflections, S178

—resumé preparation, S176

—seed company, pathology role, S177

Carisse, O., 1273

Carreño, N., 82

Carrère, S., 1105

Carrot

- cavity spot, fungicides in California, S34

-root-knot nematode, nematicides, S95

Cartolaro, P., 411

Castagnaro, A. P., 38

Casuarina equisetifolia, decline, Guam, S85

Cauliflower mosaic caulimovirus, capsid protein, whitefly transmission, S153

Cauliflower mosaic virus, on canola, Iran, S43

Centaurea solstitalis, rust, teliospore priming, 67

Cercospora, photoperiod, pathogenesis, S153

-C. beticola, on sugar beet, conidia and factors, 796

-C. depazeoides, on elderberry, pruning, S54

-C. kikuchi: protein profiles, S20; on soybean, detection, S197

Cereal, fungal interaction, regulators, S167

Ceresini, P. C. (Brazil), 1090

Céspedes, M. C., 82

Chadœuf, J., 411

Chakraborti, D., 1245

Chandelier, A., 792

Chastagner, G., 792

Cheatham, M. R., 1228

Chen, C. J. (Nanjing), 95, 1403

Chen, J. (Calif.), 236

Chen, J. (China), 258

Chen, L. F. (Calif.), 101

Chen, T.-M., 1312

Chen, X. M., 1209

Chen, Y., 441

Chenopodium quinoa, downy mildew, resistance, S184

Cherry

-brown rot, pattern in Hungary, S33

-leaf bronzing, copper-based fungicides, S47

Chestnut

—blight, virus mediated recovery, S123

-disease status in Korea, S70

- seed rot, storage,

Chiavegato, E. J., 659

Chitrampalam, P., S23 
Cho, Y. C., 243

Chondrilla juncea, biocontrol agents, S19

Chrysanthemum stunt viroid, RNA, in vitrotranscribed, 58

Cicer arietinum, Fusarium wilt, race 1, DNAAFLP analysis, 1245

Citrus

-Alternaria alternata, host-selective toxin, 369

- Asiaic canker, eradication, 1370

-bacterial spot and canker, resistance, S30

-blight disease survey, Turkey, S62

- 'Candidatus Liberibacter americanus' and 'Candidatus Liberibacter asiaticus', transmission efficiency, 301

- 'Candidatus Liberibacter asiaticus', genome sequencing, S157

- canker, chemical soil drenches, S46

- disease survey in Florida, S57

-huanglongbing: Brazil, S156; 'Candidatus Liberibacter asiaticus' association, 480; China, S28, S156; diagnosis, S157; disease, mixed population, S205; distribution, 139; endophytes, S129; epidemiology in USA, S157; genotypes and environment, 1346; India, S157; Koch's postulates, S157; management, S120; phage genomes, S38; South Africa, S157; status, S156; susceptibility, S107; translocase, S133

—Lucid tool, identification, S117

-Penicillium molds, postharvest control, S133

- post-harvest decay, control, S181

- scab, on citrus, world collection, genetics, 721

Citrus leprosis virus $\mathrm{C}$, in citrus, PCR for detection, S96

Citrus sinemsis, 'Candidatus Liberibacter asiaticus', analyses, 50

Citrus tatter leaf virus, on lemon trees, genome sequence, 423

Citrus tristeza virus

—aphid transmission: genes, S45; variance, 1168

— genetic diversity, California, S147

- genotype detection, PCR, S111

-mild and severe isolate, discrimination, 307

- population dynamics, genotype groups, 1297

Citrus yellow shoot disease, phytoplasma, China, 236

Civerolo, E. L., 236

Cladosporium caryigenum, sporulation, on pecan, S101

Clavibacter michiganensis

- disinfectant sensitivity, S9

- on tomato, seed detection, S66

Clover yellow vein virus, Bean yellow mosaic virus cross-protection, 251

Cochliobolus spp.

-C. heterostrophus, on maize, transcription encoding gene, S149

- C. miyabeanus, brown spot, Minnesota, S19

$-C$. sativus, on barley, virulence in North Dakota S49

-C. victoriae, on oat, resistance and susceptibility convergence, $\mathrm{S} 167$

Coffea arabica, berry disease, fungicides, Kenya, S60

Coffey, M. D., 390

Cohan, Y. D., 169

Colletototrichum spp.: chitosan effect, S33; on strawberry, PCR for detection, S107

-C. acutatum, on almond, characterization in Australia, 985; on blueberry, inoculation technique, S86; on blueberry, temperature effect, S86; on Capsicum baccatum, resistance genes, 1100; on citrus, flower extract effect, S78; on fruit crops and leatherleaf fern, host range, 620; on olive, disease cycle, 548; on olive, germination effect, S88; strobilurin sensitivity, S101; on strawberry, survival, S183

$-C$. cereale, on bluegrass, irrigation on putting greens, S195
-C. coccodes, on potato, potassium effect, $\mathrm{S} 41$

- C. gloeosporioides: on camellia, model, 378; on mango, control, S190

$-C$. gossypii, on cottton, field and controlled environment, 659

-C. higginsianum, metabolism, virulence, S20

Collins, G. C., 985

Computer

-Adobe connect, use, S176

-disease delivery systems, S175

- eXtension.org, information delivery, S176

- online outreach, Phytophthora training, S175

Coniothyrium minitans, Sclerotinia spp. sclerotia, relation, $\mathrm{S} 23$

Conway, W. S., 636

Cook, D. C., 1387

Cooke, P., 480

Copes, W. E., 378

Corn (see also Maize, Zea mays)

- anthracnose, residue effect, S59

-bacterial wilt and leaf blight, Indiana, S143

- foliar fungal diseases, rotation and tillage, S59

- foliar fungicides, hail damage, S15

- mycotoxins, South Dakota, S22

-nematodes, Georgia, S199

- pathogens in Puerto Rico, S135

- pitch canker, evolution, S126

-root rot, cover crop, S87

- seedling fungi, Mazandaran, S35

- yield factors, Alabama, S50

Cornus florida, Fusarium spp. hazard, S87

Correa-Victoria, F. J., 1078

Correll, J. C., 1078

Corynespora cassiicola, host specialization, phylogenetic diversity, 1015

Cotton

— foliar fungicides, S143

-management, brassica amendments, S197

—ramulosis disease, field conditions, 659

Coutts, B. A., 1156

Cover crops, tomato and pepper, organic production, Alabama, S95

Cover photo

-Aceria mangiferae, symptoms and structures, February

-Capsicum annuum, Pythium myriotylum, symptoms, May

-Effect of light on production of citrus greening symptoms, December

-European mountain ash ringspot-associared virus, symptoms on ash, April

-Fusarium mangiferae, conidia, February

-maize, phytoplasma, Reptalus panzeri transmission, September

-Monolinia spp., germination on potato dextrose agar, October

-Ophiostoma novo-ulmi, on elm, callus, June

-Papaya ringspot virus, November

- periwinkle, citrus huanglongbing-associated phytoplasma, March

- pumpkin, curly top, leafhopper tramsmission, January

- soybean, infiltration with Escherichia coli, August

—Ulmus americana, Ophiostoma novo-ulmi, callus, June

—Verticillium longisporum, on oilseed rape, resistance, July

Cowger, C., 320, 840

Cowpea chlorotic mottle virus, beetle vector, capsid protein, $\mathrm{S} 83$

Coyne, C., 1281

Cranberry, fairy ring, biocontrol, $\mathrm{S} 103$

Cronartium ribicola

- phylogeographic structure, intercontinental, S64

- on Ribes, site by year interaction, S92

-on western white pine, Canada, S94

- on whitebark pine, resistance, S122

Crop rotation, Rhizoctonia and Pythium spp., incidence and distribution, S115

Crow, G., 879

Cryphonectria parasitica, hypovirulent isolates, S199

Cryptococcus spp.

-C. flavescens, Fusarium head blight suppressed by, $\mathrm{S} 115$

-C. laurentii, on apple, postharvest biological control, 258

Cryptosphaeria spp., on cottonwood, California, S186

Cryptosporiopsis perennans, postharvest, control methods, S133

Cubeta, M. A., 166

Cucumber, soilborne pathogens, biocontrol, organic, S111

Cucumber mosaic virus

—aphid vector, Midwest epidemic, S95

—detection, PCR assay, S59

Cucurbit

-bacterial fruit blotch, evolutionary lineages, 913

- curly top disease, leafhopper transmission, 101

- downy and powdery mildew, fungicide resistance, S144

-Potyviridae reservoir, Puerto Rico, S110

-powdery mildew: Florida, S198; fungicide sensitivity, S82

- seedlots, pathogen detection, methods, 666

Cucurbit yellow stunting disorder virus, host range, California, $\mathrm{S} 142$

Cucurbita pepo, powdery mildew, fungicides in New York, S194

Cuenya, M. I., 38

Culbreath, A., 1336

Culture collections

- future resources, S178

— genetically engineered organisms, regulations, S179

Cursino, L., 996

Curtobacterium flaccumfaciens, on dry bean, Nebraska hosts, S52

Cuscuta indecora, huanglongbing vector, to periwinkle, S52

Cvrkovic, T., 1053

Cydonia oblonga, rust, etiology in Spain, S88

Cylindrocladium spp., on apple, quantification technique, South Africa, S127

Dactylaria pseudomanifesta, on trees, Brazil, S11

Dahlia mosaic virus, para-retroviral sequences, genetics, S3

Dahlia spp., para-retroviral sequences, Mexico, S31

Dallagnol, L. J., 116

Damsteegt, V. D., 480

Daphne laureola, bacterial soft rot, histopathology, S32

Das, S., 1245

Date palm, Fusarium wilt, diagnosis, S135

Datnoff, L. E., 116, 1015

Daughtrey, M. L., 1421

Davidson, J. M., 792

Davis, E. L., 194

Dawson, W. O., 423, 1346

Decognet, V., 185

Dedryver, F., 968

Defense signaling, resistance genes, oleic acid, S79

de Gruyter, H., 792

Delalande, M., 203

Delbac, L., 930

Deng, X., 236

Deniot, G., 203

Denman, S., 792

Denning, D., S42

Denny, T. P., 1127

Diagnosis, Southern Plant Diagnostic Network, Central America, S5

Diagnostics, regulatory agriculture, training, S117 
Diaphorina citri, on citrus, detection, DNA extraction, S104

Dickeya spp.: biovar 3, potato, S27; on pineapple, monoclonal antibodies, S101; sequence comparison, $\mathrm{S} 80$

-D. chrysanthemi, on orchid, Florida, S19

Didymella bryoniae

-on cucurbit, Acidovorax avenae co-infection, 666

-on watermelon, boscalid-insensitive isolates, S62

DiLeo, M. V., 1307

Dinesh-Kumar, S. P., S164

Diplodia pinnea, on Pinus patula, diversity, S12

Disease outbreaks, issues in USA, S159

Dixon, L. J., 1015

Dodds, J. A., 1168

Donahoo, R. S., 1070

Donnua, S., 480

Dori, I., 557

Dorrance, A. E., 957

Duan, Y. P. (Fla.), 1070

Dunkle, R., A156

Ecosystem services, plant disease, mini-review, 1228

Education, plant pathology future, S178

Elad, Y., 557

Elbaz, M., 1105

Elliott, M., 792

Elm (see also Ulmus americana)

-yellows, detection, S53

Elmer, W. H., 462

Elsinö̈ spp., on citrus, world collection, genetics, 721

Emeran, A. A., 385

Endophytes, metabolites, bioprotective, grasses, $\mathrm{S} 152$

Enterobacter cloacae

- exopolysaccaride role, S29

- genetic diversity, S101

-on onion, biology, S155

Epichlö̈ spp., on grass, endophytes, S147

-E. festucae: epifluorescence and confoca microscopy, S126; on fescue, so locus, S22

Epidemiology

-autoinfection, polycyclic foliar disease, letter to editor, 1116

-IPM adoption, barriers, S174

-risk assessment history, S173

—uncertainty sociology, S174

-weather-based decision, risk, S174

Equisetum arvense

-silicon absorption, S192

- silicon transporters, S46

Errata: vol. 98(12):1252-1260, 2008，122; vol 99(3):265-273, 2009, 632

Erwinia spp.

-E. amylovora: on apple, antagonistic bacteria and yeasts, 571; on apple, antibiotic, Mexico, S109; on apple, epiphytes, S105; on apple, multi-vector transformation, S191; on apple, resistance induced by prohexadione-calcium, 591; on apple and pear, detection, S127, bacteriophages, Canada, S119; biofilm in pathogenicity, exopolysaccharides, 1237; biofilms, flagellar stators, S66; gene regulatory network, S155; herbicide to antibotic, germination arrest, S50; pathogenesis, biocontrol,128; on pear and apple, plasmid, S87; on quince, pear, and apple, resistance, S104 secretion protein, virulence, S120; virulence, molecular signature, S137

-E. psidii, on guava, genetic diversity, S127

Erysiphales, database, S44

Erysiphe spp.

-E. betae, on beet, resistance mechanisms, 385

-E. necator: chasmothecia, parasitism by Am- pelomyces quisqualis, 704; on grape, epidemic analysis, 930; on grape, epidemic and modeling, 411; on grape, temperature and host susceptibility, S89

-E. polygoni, on sugar beet, sulfur for control, S62

Escherichia coli, on spinach, dissemination by flies, S139

Esker, P. D., 659, 1228

Etiology, spatial analysis, fields, S80

Eucalyptus spp., Botryosphaeriaceae, Uruguay, S102

European mountain ash ringspot-associated virus

-on ash, cover photo, April

- detection and variability, 344

Eustoma grandiflorum

-Fusarium avenaceum, phylogenetic diversity, 462

— gray mold, factors and management, 557

Exotic pests

-detection in: California, S172; detection in Florida, S172

- detection, national perspective, S172

-industry perspective, S172

-National Pest Diagnostic Network for detection, S172

Exserohilum spp., on bermudagrass, Texas, S21

Eynard, J., 696

Eynck, C., 802

Fan, P. S., 95

Faris, J. D., 282, 906

Feng, J., 913

Fernandes, N. G., 301

Fernández-Aparicio, M., 385

Fernando, W. G. D., 879

Fescue, nematode infection, susceptibility, S95

Fessehaie, A., 666

Festuca arundinacea, endophytes and alkaloids, toxicity, 1336

Fetch, T., Jr., 339

Fichtner, F. J., 608

Fig, new viruses, mosaic, S131

Filippone, M. P., 38

Fisher, A. J., 67

Filippone, M. P., 38

Fisher, A. J., 67

Floriculture, silicon in amendments, soilless media, S76

Foissac, X., 711

Folimonova, S. Y., 1346

Food safety, plant pathology contribution, S178

Foot and mouth disease virus, epitope expression, S149

Forbes, G. A., 782, 1228

Forensic

—education exercises, S160

-methods and factors, S160

-molecular tools, S160

Forest, invasive fungi, early warning system, S11

Fortunella spp., citrus canker, resistance, S36

Fourrier, C., 582

Francis, D. M., 1037

Frank, M., 220

Franke, J., 974

Frankel, S. J., 792

Frankliniella occidentalis, Tomato spotted wilt virus vector, transmission frequency, 404

Frare, G. F., 301

Freeman, S., 152, 160, 775, 985

French, R., 943

Frezal, L., 1216

Friesen, T. L., 282, 906

Fruit crops, anthracnose, host range, Florida, 620

Fry, W. E., 82

Fu, H.-C., 812

Fuji, S., 951

Fukumoto, T., 369

Fumigation -farming systems, S173

-methyl bromide alternative, S173

-Prunus replant problem, S173

-soil borne diseases, alternative technology, S173

-strawberry production, regional program, S173

Fungicides (general) (see also Fungicides, specific)

-carboxylic acid, mode of action, S169

-Fusarium graminearum on wheat, 95

-new class, synergism, S24

-Phytophthora infestans and Bremia lactucae, activity, S169

-Phytophthora spp., carboxylic acid amide, S169

-Registration Update, IR-4 Project, S128

-resistance management, dimethomorph, S170

- sensitivity distribution and resistance monitoring, S169

-spray, tomato, S23

Fungicides (specific) (see also Fungicides, general)

- aluminum chloride and sodium metabisulfite, Fusarium sambucinum and Heterobasidion annosum affected by, 167

-carbendazim and JS399-19, Fusarium resistance, 441

- chitosan, grape gray mold control, 1028

-difenoconazole, pome fruit postharvest decay, S36

—enzimidazole, Gibberella zeae and $\beta$-tubulin, 1403

-Fluopyram: broad spectrum, S36; horticultural crops control, S91

-metam-sodium, root-disease management, 362

-strobilurin: corn and cotton, S98; corn gray leaf spot control, S93

Furuya, H., 951

Furuya, N., 1062

Fusarium spp.: comparative genomics, S78; in conifers, methyl bromide, S71; DNA barcode, identification, S39; on soybean, root inoculation, S29; soybean and corn, Minnesota, S12; on Spartina alterniflora, new species, S192; spectroscopic properties, S18; on sugar beet, species differentiation, 921; on wheat, resistance in Tunisia, S41

-F. asiaticum, on wheat, sterol demethylation inhibitor resistance, 487

-F. avenaceum: on lisianthus, phylogenetic diversity, 462; on lupin, biocontrol,

-F. circinatum: on pine, detection methods, 582; resin components, strains, $\mathrm{S} 121$

-F. graminearum: ascospore discharge, mechanism, S20; carbendazim resistance, 441; fungicides,deoxynivalenol, yield, 95; mutant 8B5, S20; mutants, S197; on wheat, chemotypes, $\mathrm{S} 41$; on wheat, random-coefficient mixed models, 850; on wheat, resistance, S72; on wheat, sterol demethylation inhibitor resistance, 487; on wheat, trait locus mapping, 447; on wheat, trichothccene, S159; on wheat and rice, regulatory control, S84; zearalenone gene cluster, 176

-F. mangiferae: conidia, cover photo, February; on mango, Aceria interaction, 152; on mango, conidial dispersal pattern, 160; on mango, malformation, 775

-F. oxysporum: antagonistic strain, action mechanism, S41; on Arabidopsis, molecular interactions, S169; on cabbage, toxin, S150; on chickpea, isolate diversity, S28; on chickpea, race 1 , molecular insight, 1245 ; on cotton, soil treatment, S10; phylogenetic relations, S56; on potato, Colombia, S40; on sugar beet, variation in Iran, S10; on tomato, population structure, S55; on watermelon, acibenzolar-methyl and fungicides, S205; on watermelon, chemical and cover crop, S151; on watermelon, detection, $\mathrm{S} 21$; on watermelon, Fusarium wilt, S63; on watermelon, race 2 in South Carolina, S63

-F. sambucinum, aluminum chloride and sodium 
metabisulfite effect, 167

-F. solani: on bean, resistance souces in Uganda S90; on pea, non-host resistance, S49

$-F$ verticillioides: fumonisin, transcription factor, S78; fumonisin B1, cytochrome, S64; on maize, habitat importance, S152; on maize, virulence, S90; mycotoxin, maize, S8; protein phosphatase 2A, S119; xenobiotic detoxification, genes, $\mathrm{S} 44$

$-F$. virguliforme: host range, S66; on soybean, chromosomal polymorphism, S79; on soybean, defense genes, S106; soybean cyst nematode interaction, S37

Fusicladosporium carpophilum

-on almond: management, S36; QoI resistance, California, S35

—on nectarine, sporulation, S68

Gabriel, D. W., 1070

Gaeumannomyces graminis

-on cereals and grasses, PCR assay detection, S36

-on wheat: 2,4-diacetylphloroglucinol sensitivity, 472; epidemiological analysis, 861

Gal-On, A., 1321

Gamliel, A., 362

Gamliel-Atinsky, E., 152, 160, 775

Garbelotto, M., 390, 792

García, M. L., 38

Garnsey, S. M., 423, 1346

Garrett, K. A., 1228

Garvin, D. F., 447

Gebhardt, S., 974

Geiser, D. M., 462

Gene functions

—alternative splicing, S165

-immunity regulation, RNAs, S166

- protein farnesylation, immunity, S166

-resistance regulation, S165

Genetically engineered organisms, new roles, S65

Genomes, enterobacteria, perspective, S163

Genomic

-cyst nematode, transcript profiling, S164

-GeoChip, technology, S164

-oomycete infection, S164

Gent, D. H., 1190

Geosmithia sp., on Juglans and Carya spp., thousand cankers, S133

Geotrichum candidum, on peaches and nectarines, California, S145

Gerbera jamesonii, Fusarium wilt, S129

German, T. L., 404

Germplasm Resources Information Network, management system, S64

Gessler, C., 651

Ghanbarnia, K., 879

Gibberella spp.

-G. fujikuroi, on pineapple, South Africa, S58

- G. zeae: on barley, North Dakota and Minnesota, S18; chromosome arrangement, detection, S38; on wheat, benzimidazole resistance, 1403; on wheat, deoxynivalenol, 759; on wheat, deoxynivalenol, post-anthesis moisture, 320; on wheat, phage for control, S46

Gilbertson, R. L., 101

Gilligan, C. A., 861, 1370

Gindro, K., 1273

Ginseng, foliar diseases, jasmonic acid, S89

Giosuè, S., 453

Glandorf, D. C. M., 472

Gleason, M. L., 659

Glenn, A. E., 1336

Globodera spp., on potato, spread in Australia, 1387

-G. rostochiensis: on potato, parasitism gene, S23; stylet secretion, cellulases, 194

Glover, K. D., 759

Gobbin, D., 651

Goheen, E. M., 792
Gomi, K., 369

González, A., 82

González-Candelas, F., 765

Gordon, T. R., 67, 582, 1228

Gosme, M., 823

Goss, E. M., 792

Gottwald, T. R., 1370

Govers, F., 1150

Goverse, A., 194

Gowda, S., 423, 1346

Goyeau, H., 869

Granke L. L., 1258

Grape

-bacteria and nematodes, management in California, S185

-bacterial pathogens, simultaneous infection, S9

- Botrytis rot, gibberellic acid, S193

—canker, pruning, S186

-disease management, S74

- downy mildew, quarantine in Uzbekistan, S80

- downy and powdery mildew: management, epidemic analysis, 930; organic fungicide, S108

— esca and Petri disease, Iran, S8

-Eutypa lata, population diversity, S108

- gray mold, chitosan for control, 1028

- gray mold and powdery mildew, new fungicide, S42

-leafroll: amploviruses in vectors, 1177; California, S44

—ochratoxin A, Illinois, S31

-Pierce's disease: abscisic acid, S85; biocontrol, S54; Central American origin, S95; cold therapy, S184; sharpshooter vector, S170

- powdery mildew: air sampling, S25; Ampelomyces quisqualis as parasite, 704; biorational mixture, S192; epidemic and modeling, 411; resistance, S184; sun effect, S6; Virginia creeper, S192

-rhizospere and endophyte communities, California, S100

- sour rot, etiology in Ontario, S81

-viruses: status in Washington, S83; wild species, S44

Grapevine fanleaf virus

— genetic diversity and recombination, 1394

— genetic variability, California, S96

- origin, S195

—variability, Washington, S49

Grapevine leafroll-associated virus, sequence analysis, China, S138

Grapevine leafroll-associated virus 3, transmission ecology, S130

Grapevine virus Q, RdRp motif, S112

Grau, C. R., 1008

Groenenboom-de Haas, B. H., 1377

Gross, J., 729

Groundnut bud necrosis virus, immunodiagnosis, S109

Growth regulator, prohexadione-calcium, apple fire blight, 592

Grünwald, N. J., 739, 792

Guenoune-Gelbert, D., 1321

Guerri, J., 307

Guidot, A., 1105

Gupta, S., 1245

Gutha, L. R., 1394

Ha, Y., 666

Hagen, M. J., 679

Hamelin, R. C., 390, 792

Hammami, W., 1142

Hammer, W., 597

Hamon, C., 203

Han, S. S., 243

Hannukkala, A., 519

Hansen, E. M., 739, 792

Hansen, J. M., 447

Hartman, G. L., 353, 1412

Hartung, J. S., 139
Hausbeck, M. K., 1258

He, Z., 1121

Helder, J., 227

Helfrich, H.-P., 974

Helminthosporium spp.

-H. solani, on potato: control, S183; polycyclic disease, S57

-H. victoriae, victoriocin, S27

Hervé, M., 203

Heterobasidion annosum, aluminum chloride and sodium metabisulfite effect, 167

Heterodera spp., on barley and wheat, identification in Pacific Northwest, S146

-H glycines, on soybean: defense genes, S147; sudden death syndrome complex, S141

Heungens, K., 792

Hickory, cankers and galls, fungi, S99

Hilf, M. E., 423

Hill, N., 1336

Hirsutella minnesotensis, environmental effect, S144

Hoch, H. C., 1177, 1258

Hockett, K., 689

Hodda, M., 1387

Hoefle, C., 220

Hogenhout, S. A., 1053

Holb, I. J., 1199

Holdengreber, V., 1321

Holterman, M., 227

Honda, A., 369

Hordeum bulbosum, stem rust, resistance transferred to barley, 339

Hosta virus $X$, cDNA clone, S27

Houde, A., 1273

Hovmøller, M. S., 89

Hu, J.-M., 812

Huang, C.-H., 1312

Hückelhoven, R., 220

Hughes, K. J. D., 390

Hughes, T. J., 1008

Hugnet, T., 203

Huigen, D. J., 1150

Humulus lupulus, downy mildew, risk prediction, 1190

Hung, T.-H., 812, 1062

Hydrangea macrophylla, leaf blight and spot, complex, S87

Hypersensitivity, Xanthomonas perforans on tomato, 1037

Hyun, J. W., 721

Iancu, G., 582

Ignacio, S., 1228

Ikotun, T., 353

Integrated pest management (see also Management)

-collaboration, overview, S184

-delivery system, S181

—education and training, S53

Ioos, R., 582

Irfaq, M., 1265

Iris yellow spot virus

- molecular characterization, S7

-thrip vector, onion, S7

Irrigation, runoff water, bacteria, S145

Ishii, Y., 369

Ivors, K., 792

Iwanami, T., 1062

Jabaji-Hare, S., 274

Jacquet, C., 203

Jahier, J., 968

James, D., 792

Janisiewicz, W., 636

Jarausch, B., 729

Jarausch, W., 729

Jatropha curcas, leaf pathogens, Brazil, S28

Jelkmann, W., 729

Jena, K. K., 243

Jia, Y., 1078 
Jiang, D., 1090

Jiménez, P., 82

Jiménez-Díaz, R. M., 73

Jin, M., 1090

Jin, Y., 1135

Johnson, K. B., 128, 679

Johnston, P. A., 339

Jones, D. C., 432

Jones, J. T., 194

Jones, R. A. C., 512, 1156

Jovic, J., 1053

Juglans spp.: Brenneria rubrifaciens, genetics,

145; Phytophthora spp., resistance, S17

- J. nigra, twig beetle and canker, Colorado, S128

-J. regia, crown gall, surfactants, $\mathrm{S} 187$

Jurick, W. M., II, 636

Kallinen, A. K., 344

Kanaskie, A., 792

Kang, S. K., 721

Kanzaki, N., 1365

Karim, N., 1365

Karlovsky, P., 802

Karssen, G., 227

Kastelein, P., 1377

Katan, J., 362

Kathiravan, K., 1321

Keinath, A. P., 666

Kennelly, M. M., 591

Kessel, G. J. T., 290, 887

Khan, J., 796

Khan, M. F. R., 796

Khattak, G. S. S., 1265

Kikuchi, T., 1365

Kim, J.-S., 50

Kim, K. S., 721

Kim, Y. G., 243

King, Y.-J., 1312

Kleinhofs, A., 1135

Klemsdal, S. S., 176

Kluepfel, D. A., 145

Koczan, J. M., 591

Köhl, J., 1377

Kolmer, J. A., 750

Koopmann, B., 802

Kosaka, Y., 251

Kristensen, K., 89

Krnjajic, S., 1053

Kubisiak, T., 390

Kubota, K., 1062

Kumar, N. K. K., 404

Kwak, Y.-S., 472

Kwon, H. M., 721

Kyde, K. L., 1045

Labonne, G., 265, 632

Labyrinthula terrestris, on ryegrass, irrigation water, $\mathrm{S} 80$

Lan, C., 1121

Landa, B. B., 73

Lannnou, C., 869, 1216

Lapidot, M., 1321

Larsen, R., 1281

Latvala-Kilby, S., 519

Law enforcement, plant pathology role, S160

Lazarovits, G., 274

Lecointe, R., 203

Lectin, GAPF, broad-spectrum activity, S92

Le Goff, I., 203

Legume, root tip infection, polysaccharides, S140

Leibman, D., 1321

Leifsonia xyli, on sugarcane, detection, S111

Leng, Y., 282

Leptosphaeria maculans, on canola, infection model, 879

Lesné, A., 203

Letter to the editor

-Phytophthora ramorum on oak, nomenclature, 792
- polycyclic foliar disease, epidemiology, autoinfection, 1116

Lettuce

- powdery mildew, resistance, $\mathrm{S} 107$

- Sclerotinia drop, control methods, S81

Leveillula taurica

-on onion, host range, S43

-on tomato, forecast model, S180

Lévesque, C. A., 1273

Levite, R., 557

Levy, L., 139, 390

Lherminier, J., 1289

Li, B., 487

Li, H., 236

Li, J., 913

Li, J.-L., 50

Li, S., 1412

Li, W., 139

Liang, S., 1121

Lim, H. C., 721

Lin, F., 900

Lindberg, I. L., 344

Ling, K. S., 666

Lipps, P. E., 540, 957

Lithocarpus densiflorus, Phytophthora ramorum, survival and dispersal, 608

Liu, G., 1078

Liu, Q., 532

Liu, S., 236

Liu, X., 487

Loeb, G. M., 1177

Loehrer, M., 220

Lolium perenne, stem rust: fungicide effect, seed crop, 696; pathotype specificity, 1185; seed crops, 498

Loper, J. E., 679, 689

Lopes, S. A., 301

Lourenço, V., Jr., 765

Lozovaya, V. V., 1412

Lu, H., 258

Lucas, P., 823, 833, 861

Lygin, A. V., 1412

Lynch, S. C., 608

Lysobacter enzymogenes

-detection in soil, S147

-on fungi and algae, type IV secretion, S12

-type VI secretion, S100

Lysøe, E.,176

Ma, J. F., 116

Ma, Z., 487

Macadamia integrifolia, quick decline, control strategy, S183

MacKenzie, S. J., 620, 721

Mackey, B. E., 1028

Macrophomina phaseolina, on soybean:

-factors in Kansas, S26

-phaseolinone extraction, S113

Madden, L. V., 850

Maffia, L. A., 765

Magnaporthe spp.

-M. grisea, on rice, durable resistance, Pi40 gene, 243

-M. oryzae: conidiogenesis, genes, S146; downstream genes, mutagenesis, $\mathrm{S} 22$; on rice, conidium morphology and protein, S146; on rice, infection, $\mathrm{S} 17$; on rice, resistance genes, 900; on rice, transcriptome, S81; transcription factor genes, S29

Mahasuk, P., 1100

Maize (see also Corn, Zea mays)

-Acremonium zeae, antimicrobial activity, 109

- aflatoxin-producing fungi, land races, S98

-aflatoxins, Kenya, S158

-A. flavus resistance, involved protein, $\mathrm{S} 92$

- disease resistance, near-isogenic lines, S10

_foliar pathogens, quantitative trait loci, 540

—ochratoxin, Aspergillus spp., S99

- stolbur phytoplasma, Reptalus panzeri trans- mission, cover photo, September

Maize rayado fino virus, self-assembly in bacteria and plants, S51

Mallard, S., 968

Malus sieversi (see also Apple)

-resistance to postharvest decay, S60

Management (see also Integrated pest management)

-aerial pathogens, patchy landscape, S191

-bacteria and vectors, S160

- cucurbit virus and vectors, Florida, S171

- curly top viruses, in vegetables, S170

-decision making, cost, S174

—fungicides, Revus and Inspire, S180

- grape, downy and powdery mildew, epidemics, 930

-legume PIPE, data dissemination, S176

- lessons learned, S161

—nematode dissemination, S161

- pathogen introduction, S161

- pyrethrum ray blight, strategy, S174

-virus complexes, S184

- viruses, capsids with wings, S161

-world introductions, S160

Mango, malformation

—conidial dispersal pattern, 160

-Fusarium mangiferae cause, 775

-mite interaction, 152

Mangravita-Novo, A., 1070

Man in 't Veld, W., 792

Manuscript, preparation, author's guide, 7

Marchand, G., 1142

Margosan, D., 1028

Marsella-Herrick, P., 1177

Marssonina coronaria, on apple, early stage, S150

Martin, F. N., 390, 792

Martin, R. R., 1394

Martins, E. C., 301

Martinson, T. E., 1177

Marzachi, C., 711

Master Gardener, training program, online, S46

Masud, M. A. T., 1037

Masunaka, A., 369

Mathews, D. M., 1168

Matsushita, Y., 58

Mayer, C. J., 729

Maymon, M., 152, 160, 775, 985

Mazzola, M., 571

McCallum, B., 1355

McClean, A. E., 145

McClung, A., 1078

McDonald, B. A., 1090

McEvoy, J. L., 636

McGovern, R. J., 462

McGrath, M. J., 591

McKay, S. F., 985

McPhee, K., 1281

McSpadden Gardener, B. B., 506

McWilliams, M. G., 792

Medicago truncatula

-Aphanomyces euteiches, major gene resistance, 203

- switchgrass rust, resistance, S132

Mekuria, T. A., 1394

Meloidogyne spp.: FAME analysis, S200; phylogenetic relations, 227; protein and cell interaction, S145

$-M$. chitwoodi, on potato, resistance, introgressed, 1085

-M. incognita: on corn, management, S69; cotton, Thielaviopsis interaction, S58; on tomato, biocontrol, S140; on watermelon, grafting, S128

Melon (see also Cantaloupe)

sudden wilt, metam-sodium, 362

Meng, F., 1127

Mentha longifolia, Verticillium wilt

-resistance, S30

-timeline, S135

Menz, G., 974 
Meta-analysis

-Bayesian approach, S162

—-fire blight biocontrol, S162

-management and epidemiology, S161

- soybean rust, fungicides, S162

-treatment measurement, S161

Meterology, spatial and temporal estimation, S181

Michaud, M., 167

Microdochium nivale, on creeping bentgrass, fungicides, S66

Mielli, M. V. B., 116

Milling, A., 1127

Millus, E. A., 89

Minz, D., 985

Mitrovic, M., 1053

Miyamoto, Y., 369

Miyata, S.-I., 1062

Mizubuti, E. S. G., 765

Mlikota Gabler, F., 1028

Model

—camellia twig blight, disease progression, 378

- Cankergard, citrus canker efficacy, S13

- cascade, spatial hierarchy, 823

- disease risk, weather, S24

—disease spread, spatial hierarchy, 833

-Fusarium head blight of wheat, yield, 850

- grape powdery mildew, epidemics 411

- Horsfall-Barratt scale, testing, S13

—onion rust, temperature and wetness, 951

-Phoma stem canker on canola, rainfall and temperature, 879

-Phytophthora infestans, scenario approach, dispersal, 887

-potato late blight, pathosystem, spatiotemporal, 290

- stem rust on ryegrass, fungicide, 696

-weather estimation, case study, S185

-weather forecasting and crop disease, cyberinfrastructure, S7

-wheat streak mosaic, space approach, 432

-yellow-cedar decline, dormant volcano, S52

Mohammad, T., 1265

Mojtahedi, H., 1085

Mongkolporn, O., 1100

Monilinia spp., on stone fruit, selective media, 1199

-M. fructicola: cutinase gene, caffeic acid effect, $\mathrm{S} 23$; on peach, characterization in Mexico, S110; on peach, fungicides, S3; on peach, QoI fungicide, S193

-M. fructigena: on apple, management in organic orchards, S54; sequence analysis, China, S151

$-M$. laxa, on cherry, fungicide sensitivity, New York, S135

Moniliophthora perniciosa

-on cacao: control products, S25; gibberellin production, $\mathrm{S} 40$

Monolinia spp., germination on potato dextrose agar, cover photo, October

Monosporascus cannonballus

-ascospore germination, rhizosphere, S123

- on melon, metam-sodium, 362

Monteiro, J. E. B. A., 659

Montero-Astúa, M., 404

Montes-Borrego, M., 73

Moral, J., 548

Moralejo, E., 792

Moreno, P., 307

Morphogenesis, Aspergillus and Fusarium spp., VeA system, S152

Moya, A., 765

Mullen, R. W., 957

Mundt, C. C., 1116

Muñoz Ledesma, F. J., 73

Murphy, J. P., 840

Murray, S., 1281

Muscodor albus, biofumigant fungus, wheat bunt, S44

Mycosphaerella spp., genome plasticity, S166
-M. fijiensis, on banana, benomyl resistance in Mexico, S79

- M. graminicola: diversity in California and Kansas, S48; fungicide mutations, S37

Mycotoxin

-aflatoxin, biosynthesis gene, S54

-deoxynivalenol: Fusarium graminearum on wheat, 95; Fusarium head blight, wheat, 759; Gibberella zeae, post-anthesis moisture, 320

-zearalenone, Fusarium graminearum, gene cluster, 176

Myers, K., 82

Myrothecium verrucaria

-biocontrol, surfactant, S58

—on weeds, trichothecene production, S139

Nagabhyru, P., 1336

Nagai, Y., 951

Naglis, A., 1321

Naidu, R. A., 1394

Naito, H., 951

Nakazono-Nagaoka, E., 251

Nalim, F. A., 462

Natsuaki, T., 251

Nègre, S., 968

Nelson, C. A., 759

Nelson, E. B., 1421

Nematodes

— genomic DNA, storage, S120

-identification, DNA sequence, S51

Neonectria radicicola, on avocado, California, $\mathrm{S} 33$

Neotyphodium coenophialum, on tall fescue, endophyte and alkaloid, 1336

Nezara viridula, cotton pathogen vector, S82

Nicot, P. C., 185

Nicotiana benthamiana (see also Tobacco)

-resistance breakdown, S168

-switchgrass rust, genes, S132

- virus transmission by aphids, model, S61

Nihlgard, M., 921

Nishi, Y., 209

Nitschke, E., 921

Noe, J. P., 1336

Nomenclature

-downy mildew races, spinach, S156

-European system, S155

-race and strain naming, standardization, S155

-U.S. strategy, race and strain, S156

Nonaka, T., 209

Norman, D. J., 1070

Oat blue dwarf virus, transcripts, S31

Ocamb, C. M., 1190

Ochoa, R., 152

Oeda, Y., 1365

Ohtani, K.,369

Ojiambo, P. S., 353

Okuda, M., 1062

Olea europaea, anthracnose, disease cycle, 548

Oliveira, R., 548

Olpidium bornovanus, on cantaloupe, root infection, $\mathrm{S} 123$

Omura, T., 251

Onion (see also Allium spp.)

—Botrytis leaf blight, PCR assay, 1273

-foliar blight, resistance, S118

-rust, infection model, temperature and wetness, 951

Ophiosphaerella korrae, on bermudagrass, fungicides, S129

Ophiostoma novo-ulmi, on elm, callus

- cover photo, June

-and host defense, 642

Ordoñez, M. E., 750

Ornamentals

—pathogen registration, Cuba, S189

—rust diseases, industry, S196

-viruses, new, S29
Osborne, L. E., 759

Osterbauer, N. K., 792

Overmars, H., 194

Pacifico, D., 711

Paillard, S., 968

Palevsky, E., 152

Palm, M. E., 792

Pan, Q., 900

Panax quinquefolium, soilborne pathogens, fungicides, $\mathrm{S} 137$

Panicum virgatum, anthracnose, S72

Pantoea spp.

$-P$. ananatis, genome sequence, $\mathrm{S} 27$

-P. stewartii: on corn, resistance and forecast, S85; quorum sensing, S154

Papaver somniferum, downy mildew, herbarium specimens, detection, 73

Papaya ringspot virus

- cover photo, November

—diagnosis, Cuba, S188

-and Papaya leaf-distortion virus, double resistance, 1312

Papayiannis, L., 1321

Paratrichodorus renifer, on blueberry, North Anerica report, S35

Pariaud, B., 869

Parke, J. L., 792

Parks, R., 840

Parnell, S., 1370

Pasquini, G., 711

Passalora fulva, pathogenicity genes, Cuba, S188

Patton-Özkurt, J., 320

Pattori, E., 453

Paul, P. A., 850, 957

Paulitz, T. C., 472

Paveley, N., 861

Pea, Aphanomyces root rot, phosphorous acid, S104

Pea enation mosaic virus

—on pea, QTL resistance, S69

-seed transmission, 1281

Pea seed-borne mosaic virus, pathosystem, factors, 1156

Peach

-oxytetracycline dynamics, factors, S23

-pathogens, ecophysiological determinants, S3

Peanut

—aflatoxin, risk, S132

- Cylindrocladium black rot, Provost spray, S102

-foliar and soilborne diseases, new fungicide, S42

-fungicide movement, basipetal, S16

- fungicide sprays, S196

- fungicides, systemic, S5

-Pythium pod rot, metam-sodium, 362

-risk index, Alabama, S50

- southern stem rot, weather, S96

— spotted wilt, seeding rate effect, S197

- stem necrosis, transgenic, S7

- tomato spotted wilt and early leaf spot, China, S73

-Verticillium wilt, fumigants and fungicides, S201

Pear

-brown spot, detection in orchard, 1377

-Fabraea leaf spot, oil sprays, S195

Pecan, scab, taxonomy, S200

Pectobacterium carotovorum, on potato, enzyme activity, $\mathrm{S} 188$

Peever, T. L., 369, 532

Pelargonium sp., Pythium aphanidermatum, gnats and wounding, 1421

Pellegrini, A., 651

Pellegrini, E., 704

Penicillium spp., storage temperatures, S135

- P. digitatum: on citrus, fungicides, S93; on lime, green mold, S97; on Persian lime, chemical control, S97 
- P. solitum, on apple, polygalacturonase production, 636

Penmetcha, K. K. R., 58

Pentastiridius leporinus, endosymbionts, virus vector transmission, 1289

Pepper, begomoviruses, variability in Cuba, S190

Pepper golden mosaic virus, salicylic acid, stress, S89

Perera, M. F., 38

Peres, N. A., 620

Peretz-Alon, Y., 362

Perez Sierra, A. M., 792

Periwinkle, citrus huanglongbing-associated phytoplasma, cover photo, March

Pernezny, K., 1015

Peronospora spp.

- P. arborescens, on opium poppy, herbarium specimens, 73

- $P$. farinosa, on quinoa, resistance, $\mathrm{S} 134$

Pertot, I., 651, 704

Perugini, L., 320

Pestalotiopsis spp., on Vaccinium meridionale, Colombia, S122

Pesticide, residue photos, applicators, S26

Petrovic, A., 1053

Pfender, W. F., 498, 696, 1185

Phaeosphaeria nodorum, on wheat, genetic linkage, S132

Phakopsora spp.

-P. arthuriana, on Jatropha, Brazil, S28

- P. pachyrhizi: on barley epidermis, cell death, transgenic suppression, 220; glyceollin and lignin limitation, S77; on soybean, fungicide sensitivity, S21; on soybean, phenolic metabolism, 1412; on soybean, plant age and maturity, $\mathrm{S} 123$; on soybean, post-dew period temperature, $\mathrm{S} 14$; on soybean, resistance, S59, S99; on soybean, variation in Nigeria, 353; spore identification, in Maine, 328

Phalaenopsis spp., flower crinkle, virus, S151

Phaseolus vulgaris

-on rust, resistance in Africa, S100

-Sclerotinia white mold, QTL linkage map, S86

Phelipanche sp., virus acquistion, 1321

Phialophora gregata, on soybean: IGS genotypes A and B, PCR assay, 1008; monoculture, S56; types A and B, S78

Phoma spp., weed control, evaluation, S10

-P. sclerotioides, on alfalfa, brown root rot, $\mathrm{S} 143$

Phomopsis spp.

-P. longicolla, on soybean, detection, S34; on soybean, resistance, $\mathrm{S} 72$; on grape, transformation, S4

Phymatotrichopsis omnivora

—on alfalfa, New Mexico, S114

-on cotton: fungicides and irrigation, S198; phylogeography, S79

Phytophthora spp.: on Capsicum annuum, races, S88; cyberinfrastructure, Pythium database, diversity in floriculture crops, S109; effector and resistance protein interaction, $\mathrm{S} 50$; evolutionary biology, S162; forest ecology, S163; forest paradigms, S162; identification tool, S47; identification, training course, S100; irrigation water in nurseries, S54; irrigation water, recycled nursery, Texas, S124; in nurseries, recovery, S100; nurseries in Tennessee, S114; on ornamentals, North Carolina, S97 population diversity, S162

- P. capsici: on bell pepper and cucurbits, fungicide sensitivity, S57; on cucumber, fruit development, S142; on cucumber and pepper, AG3 phosphonate, S1; on Cucumis melo, S29; haplotypes, Texas, S37; iprovalicarb resistance, S77; irrigation ponds, Georgia, S137; mandipropamid sensitivity, S67; on pepper, biocontrol, S74; on pepper, mandipropamid sensitivity, S70; on pepper, resistance, S203; phylogeny and diversity, New Mexico, S51; on pumpkin, chemical control, S6; races, S88; on squash, acquired resistance, S67; on squash, chemical application, S149; on squash, rhizobacteria, greenhouse, S149; sodium salicylate and Neem, hydroponic amendments, S98; sporangia, dispersal and mechanisms, 1258; sporangia, mechanisms, S46; on tomato, resistance, S106; on yellow squash, Michigan, S142

$-P$. cinnamomi: forest soil, spatial distribution, S82; mulching systems, biocontrol, S122; on Quercus spp., biofumigants and organic amendments, S134; rain forest soil, Brazil, S77

-P. citricola, zoospores, in soil, S96

-P. infestans: A2 mating type, Colombia, 82; cold temperature tolerance, genetics, S130; dispersal, scenario approach, 887; mating, inheritance recombination, S130; on potato, genotype susceptibility, 782; on potato, genotypes, temperature, $\mathrm{S} 65$; on potato, migration in China, S48; on potato, race recognition, 1150; on potato, resistance, S64; on potato, spatiotemporal model, 290; on potato, tuber proteins, S34; on potato and tomato, pyrimidine biosynthesis pathway, S39; RNA virus from, $\mathrm{S} 18$; spore types, fungicides, S96; on vegetables, rice residues and swine manure effect, S114; virulence determinants, bioinformatics, S120

-P. inundata, on tobacco, Virginia, S100

- P. katsurae, on chestnut, Korea, S70

- P. kernoviae, in UK, risk in North America, S35

$-P$. lateralis, on Port-Orford-cedar, resistance, S122

-P. nicotianae, on tobacco, oospore variability, S39

-P. palmivora, on Carica papaya, genomics, S104

-P. parasitica: on tobacco: chemical control and resistance, $\mathrm{S} 4$; pathogenesis mechanism, S4

-P. phaseoli, on lima bean, genes, $\mathrm{S} 68$

$-P$. ramoram: acorn susceptibility, S205; on California bay laurel, systemic injury, 1307; Canadian forest, susceptibility, S193; clonal lineages, S32; detection and eradication, Oregon, S61; epidemiology, S32; epidemiology, mapping and models, S163; hosts, factors, Oregon, S16; on live oak, resistance, S92; migration pattern, West Coast of USA, 739; molecular markers, isolate library, 390; on oak, nomenclature, letter to editor, 792; on ornamentals, diversity in Washington, S181; pathogenicity, S163; on red oak and chestnut oak, sporulation, S205; on redwood-tanoak, survival and dispersal, 608; on Rhododendron, detection, S205; on Rhododendron, fungicides, $\mathrm{S} 180$; on rhododendron, temperature and moisture effect, 1045; on tanoak, eradication, S61; on tanoak, genotypes, S16; on tanoak, molecular scale, S15; variation, migration pathways, S45

-P. sansomeana, on soybean, root rot, $\mathrm{S} 107$

-P. sojae: elicitin genes, down regulation, $\mathrm{S} 148$; oomycete effectors, S167; on soybean, kinase regulation, $\mathrm{S} 32$

Phytoplasma

- aster yellows:leafhopper transmissibility, S38; Ohio crops, S31

—phylogenetic analysis, S70

-stolbur, Bois noir isolates, 711

Pianzzola, M. J., 1105

Pickering, R., 339

Pilet-Nayel, M.-L., 203

Pine

-loblolly: decline analysis, S8; fusiform rust, S136

-lodgepole, combat disease, defense, S136

-longleaf and loblolly, decline, Georgia, S148

Pineapple, badnaviruses and retrotransposons, Hawaii, S118
Pineapple mealybug wilt associated virus-2, vectors, Hawaii, S125

Pinus spp.: Fusarium circinatum, detection methods, 582; seedling disease, Proline for control, S200; wilt, spread to Kansas, S63

-P. albicaulis, white pine blister rust, Western USA, S90

-P. monticola, blister rust, protein, $\mathrm{S} 75$

- P. resinosa, Diplodia shoot blight, understory seedlings, S95

-P. taeda, starch grains and cambial cells, S201

Pistachio, panicle and shoot blight, warning system and sprays, S89

Pisum sativum, powdery mildew, alternative hosts, S5

Pivonia, S., 557

Plant health, doctor, interdisciplinary program, S43

Plant tests, movement in Caribbean, S70

Plasmodiophora brassicae, on canola, seeding date, S45

Plasmopara viticola, on grape, epidemic analysis, 930

Ploper, L. D., 38

Plum pox virus, Oregon survey, S116

Pochonia chlamydosporia, nematodes, biocontrol, S189

Podosphaera spp., on hop and cherry, PCR assay, S75

-P. xanthii, on squash, resistance, $\mathrm{S} 194$

Pokeweed mosaic virus, sequencing, S112

Poling, S. M., 109

Popeijus, H., 194

Postharvest pathology

- grape gray mold, chitosan, 1028

- nectarine, biocontrol, S58

-Penicillium solitum on apple, polygalacturonase, 636

Postnikova, E., 480

Potato (see also Solanum spp.)

- apoplastic response, protease, S34

_black dot, nitrogen, S12

—brown rot, strain detection, 1105

-cyst nematode: detection, S158 ; spread in Australia, 1387

—early dying, S 158

-late blight: forecasting models, S122; genotype susceptibility, 782; management strategy in Ecuador, S8; race recognition, 1150; spatiotemporal model, 290

-nematodes, quality effect, S158

- pink rot: biocontrol in storage, $\mathrm{S} 67$; calcium effect, S180

-root-knot nematode, resistance, 1085

-scab: field gene, S138; suppressive soil in Michigan, S84

—-soilborne disease, cropping system, S69

-soilborne diseases, S158

-Verticillium wilt: green manure, S181; metamsodium, 362

-viruses, Iran, S42

-yellows and zebra chip, differences, S117

—zebra chip disease, seed tuber infection, S52

-zebra complex disease, S3

Potato mop-top virus, on potato, detection, symptomless infection, 519

Potato spindle tuber viroid, Russian isolates, diversity, $\mathrm{S} 98$

Potato virus $S$, on potato, properties, S74

Potato virus $Y$

- aphid vector, S83

- detection in Iran, S89

_integrated pest management, S47

-on potato, tuber symptoms, S141

-resistance and molecular markers, 187

Potato yellow vein virus

-latency in tubers, S37

-leaf and tuber detection, Colombia, S189

-Solanum phureja, Colombia, S36 
Potebniamyces pyri on pear

—diagnosis, S75

-population structure, markers, 532

Pradel, W., 1228

Prado, G. A., 1078

Prarr, R. C., 1053

Prathuangwong, S., 996

Prats, E., 385

Pratt, R. C., 540

Pratylenchus spp.

—on barley and wheat, tolerance, S121

-on biofuel crops, distribution, S84

- phylogenetic relations, 227

Prince, R. T., 1156

Prior, P., 1105

Prodorutti, D., 651

Programmed cell death, host-pathogen interaction, ribosylation, $\mathrm{S} 16$

Prospéri, J.-M., 203

Prospero, S., 739, 792

Prunus spp.

- 'Candidatus Phytoplasma prunorum', transmission efficiency, 265, 632

-viruses in orchards and nurseries, Pennsylvania, S90

Pseudomonas spp., Aspergillus flavus and Fusarium verticillioides affected by, on soil and in air, S99

-P. chlororaphis: biofilm, antibiotics, S154; metabolites, Fusarium inhibition by, $\mathrm{S} 183$

-P. fluorescens: antibiotic produced by, nematode effect, S85; biocontrol agent, factors, 679; 2,4diacetylphloroglucinol produced by, seed treatment, 506; Fusarium suppression, rhizoctin and diacetylphloroglucinol, S106; growth promotion, type III secretion system, S140; RpoS role, stress and environment, 689; siderophore and iron uptake, S52

- $P$. syringae: leaf fitness, choline, $\mathrm{S} 9$; quorum sensing and epiphytic fitness, factors, S154, siderophore role, S141; on sweet cherry, wound infection, S123; on tea, environmental control, 209; transcriptome I and II, S163; on wheat, biocontrol, S146

Pseudoperonospora spp.

-P. cubensis: on cucumber, management, S188, cucurbit, chemical control, S171; on cucurbit, epidemiology, S172; on cucurbit, fungicide resistance, S171; on cucurbit, long distance movement, $\mathrm{S} 171$ on cucurbit, re-emergence, S171; P. humuli comparison, host specificity, S87; P. humuli relation, management, S171

-P. humuli, on hop: management, S42; PCR detection, S33; on hop, risk prediction, 1190

Pseudozyma flocculosa

—biocontrol agent, genes, 1142

-flocculin production, analysis, $\mathrm{S} 192$

Pu, X., 236

Public policy

-APS issues, S177

-APS-OSTP fellow, perspective, S178

- career internship, APS, S177

Puccinia spp.

- P. allii, on onion, infection model, temperature and wetness, 951

$-P$. coronata, on oat, seedling and adult-plant resistance, $\mathrm{S} 1$

-P. crupinae, Crupina vulgaris biocontrol, S33

-P. emaculata, on switchgrass, interaction, S72

-P. graminis: on barley, race TTKSK, resistance, 1135; on barley, resistance from Hordeum bulbosum, 339; on perennial ryegrass, fungicide effect, 696; on perennial ryegrass, pathotype specificity, 1185; on perennial ryegrass, seed crops, 498; on wheat, fungi-toxicants, spore germination, S48; on wheat, microsatellite markers, 282; on wheat, new races, $\mathrm{S} 14$

- $P$. jaceae, on yellow starthistle, teliospore priming, 67
-P. kuehnii, on sugarcane, detection, S44

-P. pelargonii-zonalis, on geranium, detection, S116

-P. polysora, southern rust, update, $\mathrm{S} 198$

$-P$. recondite, on wheat, geostatistical analysis, 974

-P. striiformis: on barley and wheat, races, S137; heterkaryotic variation, S75; physical and genomic map, S78; on wheat, cDNA library, S61; on wheat, disease progress curve, 1265; on wheat, durable resistance and genetics, 968; on wheat, protein genes, S29; on wheat, resistance gene, 1209; on wheat, strain aggressiveness, 89; on wheat, temperature and leaf wetness, S93; on wheat, temperature and moisture effect, S31; on wheat and barley, somatic hybridization, S23

-P. triticina: gene mapping, chromosome arm 7BL, S53; on wheat, aggressiveness components, 869; on wheat, dispersal in canopy, 1216; on wheat, genotype and phenotype differentiation, 750; on wheat, haustorium specific genes, S116; on wheat, spore germination, factors, 1355

Pucciniales, taxonomy and evolution, S196

Pumpkin, curly top symptoms, leafhopper transmission, cover photo, January

Pupola, N., 519

Pusey, P. L., 571

Pyrenophora spp.

-P. teres: on barley, synthetase genes, diversity, S77

-P. tritici-repentis, on wheat: chemical treatment, genes, S101; isolate characterization, S60; necrosis gene, S101; Ptr ToxA, S2

Pyrus communis, Potebniammyces pyri, population structure, markers, 532

Pythium spp.: diversity and fungicide efficiency, Ohio, S32; green bean disease, Spain, S118; greenhouse problems, S192; on peanut, metamsodium, 362; on pine, survival, S199; soil chemical and physical properties, disease relation, 957; tree nursery, fumigation, S140

$-P$. aphanidermatum: disinfectants, Rhizoctonia comparison, S35; gnat transmission, vector capacity, S16; on geranium, gnats and wounding, 1421; on vegetable seedlings, fungicides, S9

-P. apinafurcum, phylogeny and infectivity, S133

-P. myriotylum, on pepper: cross-flow membrane filtration, 597; symptoms, cover photo, May

-P. ultimum, fish emulsion effect, 274

Qi, A., 796

Qing, L., 716

Quercus spp.

- sudden death, survival and dispersal, 608

-sudden oak death, nomenclature, letter to editor, 792

Quesada Ocampo, L. M., 82

Quince, fire blight, Bulgaria, S13

Ralstonia spp.

-R. solani, genomes, S166

$-R$. solanacearum: biocontrol with plant oil, S99; genetic diversity and host range, entering North America, 1070; immuno-capture, PCR sensitivity, S101; molecular aptamers, S20; molecular beacon for detection, S68; nematode killed by, sensing system, S78; strains, genes, S57; strain-specific traits, S166; type II secretion substrate, $\mathrm{S} 130$

Ramallo, C. J., 38

Rangi, R. K., 1245

Raspberry

-Reoviridae, on fruit, S106

-root rot and decline, fungus and nematodes, S43

Rathayibacter spp., on cereal, taxonomy, S104

Raudales, R. E., 506
Rav David, D., 557

Raymundo, R., 1228

Reatrepo, S., 82

Redinbaugh, M. G., 1053

Regulation

-exotic pest detection, S17

- genetically engineered pathogens, shipping, S178

-pathogen movement by mail, Caribbean, S34

- pests and pathogens, status, S177

Rehman, S., 194

Rémus-Borel, W., 1142

Reptalus panzeri, phytoplasma transmission, on maize, Serbia, 1053

Resistance

—approaches and challenges, S168

-barley to: stem rust, chromosomal location, 339; stem rust, race TTKSK, 1135

-beet to powdery mildew, mechanisms, 385

- Brassica napus to Verticillium wilt, 802

-breeding and pathology tools, S185

-Capsicum baccatum to anthracnose, resistance genes, 1100

-durable disease control, pattern recognition, S108

-major R gene function, mechanism, S168

-Medicago truncatula to Aphanomyces euteiches, major gene, 203

-metabolites and toxins, S168

-non-host, pea PR genes, S49

- papaya to transgenic papaya, two viruses, 1312

-potato to: late blight, genotypes, 782; root-knot nematode, introgressed, 1085

-rice to: blast, Pi40 gene, 243; blast, genes, Pik-p cluster, 900; sheath blight, quantitative trait loci, 1078

— systemic acquired, cuticle role, S39

-tomato to: bacteria, bacterial wilt, molecular response, S169; tomato to bacterial spot, race T3, 1037

-wheat to: Fusarium head blight, wild emmer chromosome, 447; powdery mildew, quantitative trait loci, 1121; Stagonospora nodorum blotch, tetraploid population, 906; stripe rust, genetics, 968; stripe rust, molecular mapping, 1209

Reviewers, acknowledgment, 4

Rhizoctonia spp.: on rice, diversity and population in Arkansas, S19; species differentiation, markers, S113; on turfgrass, Maryland and Virginia, S3

- R. solanacearum: on potato, strain detection, 1105; race 3 biovar 2, temperature effect, 1127

$-R$. solani: anastomosis groups, identifcation, S188; on Brassica spp., resistance screening, $\mathrm{S} 180$; on fescue, chitinase assay, S26; on Festuca arundinaceae, nutrient and yeast effect, S94; on pea, AG-5, North Dakota, S45; on rice, Ag-1Ia from China, genetics, 1090; on potato and sugar beet, on rice, resistance, quantitative trait loci, 1078; on potato and sugar beet, variability, S113; protein identification, S68; on sugar beet, crop rotations, S15; on tomato, AG3, S57; on vegetables, management in New York, S194; on zoysiagrass, Arkansas, S123

Rhodococcus fascians, on ornamentals: detection, S117; PCR for detection, S93

Rhododendron spp.: on ornamentals Phytophthora ramorum, temperature and moisture effect, 1045; Petuvirus, S112; powdery mildew, taxonomy in Pacific Northwest, S105

Rice

-bacterial blight, major gene, S5

-bi-directional promoter, report genes, S150

-blast: appressorial development, S204; detoxification, S204; durable resistance, Pi40 gene, 243; effector translocation, S167; resistance genes, mapping, 900; resistance, S19; resistance genes, S148 
-brown spot, silicon uptake, 116

—false and kernal smut, management, S17

-management, tissue culture and transformation, S189

- sheath blight, resistance and quantitative trait loci, 1078; sheath blight, Rhizoctonia Ag-IIA, genetics, 1090; sheath blight and blast, biocontrol, S22

- sheath spot, control products, S20

-wheat rotation, Mazandaran, S35

Rice, J. T., 472

Riga, E., 1085

Rioux, D., 167, 642

Rizzo, D. M., 608, 792,1307

Robbins, M. D., 1037

Robert, C., 869

Robert, O., 968

Robertson, C. J., 1346

Rochas, A., 930

Rodrigues, F. Á., 116

Roesleria subterranea, on grape, Michigan, S86

Roh, J. H., 243

Rojas, A., 82

Romanazzi, G., 1028

Rose yellow vein virus, on rose, transmission, S87

Rossi, V., 453, 1377

Rossing, W. A. H., 290, 887

Rotenberg, D., 404

Rotylenchulus renoformis

-on cotton: radish cover crops, S117; soil type effect, S199

—fungi for control, microplot, S196

Rouse, M. N., 1228

Roy, A., 1297

Rubiales, D., 385

Rubus spp., pararetrovirus, genome, S60

$-R$. idaeus, virus, detection in Alaska, S109

Rudbeckia hirta, seed-borne virus, flower distortion, S76

Ruiz-Ruiz, S., 307

Rumohra adiantiformis, anthracnose, host range in Florida, 620

Rupestris stem-pitting associated virus, on grape, molecular diversity, $\mathrm{S} 2$

Rush, C. M., 432

Sagaram, U. S., 50

Saguaro cactus virus, capsid protein, silencing, S141

Salinari, F., 453

Sanderson, J. P., 1421

Sasaya, T., 251

Sauvion, N., 265, 632

Savary, S., 930

Sawyer, T. L., 128

Schaad, N. W., 480, 913

Schaffrath, U., 220

Schlub, R. L., 1015

Schnabel, G., 1199

Schneider, W. L., 480

Schuenzel, E. L., 480, 913

Schuerger, A. C., 597

Schultheiss, H., 220

Sclerotinia spp.: Contans ${ }^{\circledR}$ for control, soil, S116; on peanut, lesions, $\mathrm{S} 17$

-S. homoeocarpa: on creeping bentgrass, wound effects, S97; epidemic modeling, S121; fungicides, golf course, S194; secretome analysis, S107; soil temperature effect, S142 secretome analysis, S107; on turf: fungicides and climate, S66; genetics in North America, Asia and Europe, S201; sequence analysis, S127

-S. sclerotiorum: on canola, biofungicide, S136, on canola, resistance, S18; inoculum fitness, media, S105; on peanut, melanin and pathogenicity, S77; on soybean, biocontrol products, $\mathrm{S} 148$; on soybean, NLP1 and NLP2 genes, S80; sclerotial germination, S92; on sunflower, resistance, $\mathrm{S} 13$
-S. trifoliorum, on chickpea, genetic diversity, S94

Sclerotium rolfsii, on orchid, Florida, S19

Scott, E. S., 985

Sebacina vermifera, on switchgrass, drought tolerance, $\mathrm{S} 43$

Sechler, A., 480

Sedgley, M., 985

Sémétey, O., 1289

Senna surattensis, phytoplasma, China, S143

Sentelhas, P. C., 659

Septoria spp. on poplar, DNA bar coding, S51

-S. pistaciarum, on pistachio, leaf spot in New Mexico, S37

Serratia marcescens, on cucurbit, transmission, S170

Setosphaeria turcica, on corn, China, S150

Shah, S. J. A., 1265

Shamoun, S. F., 792

ShiDong, L., 1090

Shimizu, T., 251

Shishkoff, N., 792

Shpialter, L., 557

Shtienberg, D., 160, 775

Sim, S.-C., 1037

Simard, M., 167, 642

Siri, M. I., 1105

Sirococcus clavigigmenti-juglandacearum, on butternut, detection, S16

Skelsey, P., 290, 887

Smant, G., 194

Smart, C. D., 1258

Smilanick, J. L., 1028

Smith, L., 67

Snook, M. E., 1336

Soil amendments, fish emulsion, effect on Verticillium and Pythium, 274

Soil disinfestation, Phytophthora capsici and Verticillium dahliae, effects, S18

Soilborne diseases

—almond and cherry, detection, S11

- study method, S10

Soilborne pathogen, quantification, PCR, S186

Solanum spp., R gene mapping, S15

Sonchus yellow net virus, minireplicon, GFP expression, S39

Sonder, K., 353

Sorbus spp.

$-S$. aucuparia, European mountain ash ringspotassociated virus, genetic variability, 344

$-S$. scopulina, ring spot leaf, virus association, S185

Sorghum, mycotoxigenic fungi, detection, S107

Soybean

—bacterial pustule, virulence specificity, 996

—begomoviruses, Nigeria, S3

-brown stem rot, genotypes A and B, PCR assay, 1008

-Cercospora kikuchii and Diaporthe phaseolorum, seed infection, S132

- cyst nematode: detection, S76; hosts in Great Plains, S103

-disease survey, Alabama, S120

-Escherichia coli leaf infiltration, cover photo, August

—foliar diseases and yield, fungicides, S11

-frogeye leaf spot, molecular analysis, S53

-fungicide and insecticide applications, S122

-pathogen immunity, gene silencing, S38

- Phytophthora sojae, pathotypes, S124

-rust: epidemiology in Florida, S148; four-year evaluation, S200; GIS analysis, S91; phenolic metabolism, 1412; spore detection, S136

-spore identification, in Maine, 328; uredinia, S201; uredinia co-inhabitants, S138; variation in Nigeria, 353

-seed rot and damping-off, fungi and cropping system, S74

-seed treatments, temperature, S132

- sudden death syndrome: factors, S45
Soybean dwarf virus, RNAs, encapsidation, S128

Soybean mosaic virus, evolution toward virulence, mutations, $\mathrm{S} 50$

Soybean vein necrosis virus, new threat in USA, S131

Sparks, A. H., 1228

Sphaerotheca fuliginea, on cucumber, biofungicides, S125

Spinach, white rust, fungicides, S129

Spink, J., 861

Spore trap, electrostatic, fluorescent antibody and

PCR protocols, S115

Squash vein yellowing virus, on cucurbits, distribution, S139

Stack, R. W., 447

Stagonospora nodorum, on wheat, Tsn1-ToxA interaction, tetraploids, 906

Staphylococcus spp., on horses, coagulase, S14

Steffenson, B. J., 1135

Stein, J. M., 759

Steiner, B., 362

Stemphylium vesicarium, on pear, detection in orchard, 1377

Stockwell, V. O., 128, 571, 679, 689

Stone fruits

-Cytospora canker, plant oil effect, S103

-shoot-tip culture system, disease-free rootstocks, S62

Stone, A. L., 480

Stone, E., 506

Storari, M., 1090

Strawberry

- gray mold, management, S25

- powdery mildew, epidemic, S124

—sting nematode, methyl bromide, S94

-Verticillium wilt: fumigation and compost, S11; resistance screening, $\mathrm{S} 135$

Streptomyces spp.: apple rhizosphere, seed meal amended soil, S150; global geography, antagonism, S115; plant signaling compounds, S7

-S. scabies, pathogenicity mapping, S167

Su, H.-J., 812, 1062

Subandiyah, S., 1062

Sugar beet (see also Beta vulgaris)

—bacterial root rot, cultivars, S125

-biocontrol agents, microparasites, S52

- Cercospora leaf spot, conidia and disease severity, 796

- collar rot, management, S22

-Fusarium spp., species differentiation, 921

- glyphosate effect on disease, S76

-Rhizoctonia crown and root rot, remote sensing, S108

-Rhizoctonia damping-off, pH effect, S139

-soilborne diseases, detection, S53

-soilborne viruses, Iran, S15

Sugarcane

-Aspergillus flavus, section, aflatoxins, S40

-leaf scald, resistance, S40

Sugarcane mosaic disease, genetic diversity, Argentina, 38

Sugarcane streak mosaic virus, nucleotide sequence, $\mathrm{S} 144$

Sugarcane yellow leaf virus

- control in Ecuador, S40

-postharvest residue, S46

Suh, J. P., 243

Sui, X. X., 1209

Sun, Y., 1135

Sundin, G. W., 591

Surghum, grain mold fungi, protein, S94

Synchytrium spp.

-S. endobioticum, on potato, field detection, S24

- S. solstitiale, germination in greenhouse, S203

Szabo, L. J., 282, 328

Sztejnberg, A., 152, 160, 775

Taisant, G., 930

Takahashi, T., 251 
Takanashi, H., 951

Tatineni, S., 423, 943

Taylor, P. W. J., 1100

Teixeira, D. C., 301

Temple, T. N., 128

Teratosphaeria nubilosa, on Eucalyptus nitens, South Africa, S102

Tessitori, M., 711

Thaveechai, N., 480

Thébaud, G., 265, 632

Theobroma cacao, defense genes, Bacillus spp. S204

Thomson, J. L., 378

Tillage, soil bacterial communities, rotations, S147

Tilletia caries, on wheat, genetic diversity, S81

Timmer, J. W., 620, 721

Timmerman-Vaughan, G., 1281

Timper, P., 1336

Tobacco (see also Nicotiana benthamiana)

-barley oxalate oxidase gene, introgression, S204

-blue mold, resistance, S193

-broomrape, mocrobiota, Cuba, S189

-management, crop systems, S188

-Pythium root rot, surfactant, S116

-Pythium spp., control method, S59

-root-knot, resistance genes, S116

Tobacco curly shoot virus, Tomato yellow leaf curl China virus co-inoculation, competition, 716

Tobacco mosaic virus: disinfectants, S71; management, greenhouse, S131

Tobacco necrosis virus, on Chenopodium amaran ticolor, coat protein gene, $\mathrm{S} 72$

Tobacco rattle virus, detection with RT-PCR, S145

Tobacco streak virus, on soybean, gene silencing, S60

Tomato

-bacterial canker, seed tratment, S145

-bacterial speck, ubiquitin lyase, S168

-bacterial spot: copper, S26; race T3, hypersensitivity resistance, 1037

-Botrytis cinerea, genetic diversity in glasshouse, 185

—chocolate spot, picorna-like virus, Guatemala, S68

—early blight and target spot, azibenzolar-Smethyl, S133

-integrated control, S91

-leaf spot and late blight, resistance, Cuba, S189

- mosca blanca, vector transmission and potato, Cuba, S189

—postharvest decay, methylcyclopropene, S186

- purple top phytoplasma, gene profile, S139

-Ralstonia wilt, biocontrol, S146

—resistance, multiple, S119

- sour rot and water relation, S8

- southern blight and root-knot, grafting, S109; Tomato chlorotic dwarf viroid and Potato spindle tuber viroid, seed detection, S66

Tomato bushy stunt virus

-leaf and root inoculation, coat protein and silencing, S79

-on Nicotiana spp., hypersensitivity, S4

Tomato double streak virus, Iran, S2

Tomato infectious chlorosis virus, nucleotide sequence, $\mathrm{S} 142$

Tomato leaf curl New Delhi virus, on melon, characterization, S21

Tomato mosaic virus, resistance alleles, S119

Tomato ringspot nepovirus, on apple, Pennsylvania, S90

Tomato spotted wilt virus

-on flower thrips, S93

-Frankliniella occidentalis vector, transmission frequency, 404

-nucleocapsid protein and glycoprotein, S88

- processing tomato, California, S131

- protein domain, tubules, S71 -on tobacco: acibenzolar-mrthyl application, model, S197; Georgia, S26; soil fertility, S198

-on tomato, thrips, California, S9

-vector genomics, S110

Tomato yellow leaf curl China virus, Tobacco curly shoot virus co-inoculation, 716

Tomato yellow leaf curl virus, Kentucky, S200

Tomihama, T., 209

Tomimura, K., 1062

Tooley, P. W., 792, 1045

Tooley, P., 390

Toševski, I., 1053

Toxoptera citricida, Citrus tristeza virus vector, 1297

Trapero, A., 548

Trees, de-icing salts, effect in Lake Tahoe Basin, S91

Tremblay, D. M., 1273

Trichoderma spp.: antagonism and cellulolytic enzyme, S118; antagonist to Rhizoctonia, biocontrol, S190; colonization activity, S183

-T. virens: elicitors to toxins, S152; paralogs, elicitor, S26

Triky-Dotan, S., 362

Triticum mosaic virus

-leader sequence, 943

-long leader sequence, S127

-Wheat streak mosaic virus comparison, hosts, S117

Tropical fruit, sooty blotch and flyspeck complex, new records, $\mathrm{S} 102$

Trottet, M., 968

Trottin-Caudal, Y., 185

Tsuge, T., 369

Tugume, A. K., 344

Turf

- anthracnose, traffic effect, S109

—diagnosis and management, TurfFiles, S129

—dollar spot, Florida, S24

-Typhula spp., fungicide sensitivity, S13

Turfgrass

-fairy ring, DMI fungicide, S86

-Rhizoctonia sp., S61

Turnip yellows virus, on crucifers, China, S144

Tweddell, R. J., 167

Twizeyimana, M., 353

Ullman, D. E., 404

Ulmus americana (see also Elm)

-Ophiostoma novo-ulmi, callus and host defense, 642; cover photo, June

Umbellularia californica, Phytophthora ramorum, systemic injury, 1307

Uncinula necator, on grape, casmothecium, S6

Undifilum oxytropis, swainsonine-producing, transformation system, S90

Uromyces salsolae, Salsola tragus, biocontrol, S203

Vaccinium corymbosum, Armillaria root rot, genetic diversity in Italy, 651

Valkonen, J. P. T., 344, 519

Vanblaere, T., 651

van den Bosch, F., 1370

van den Elsen, S., 227

van der Werf, W., 290, 887

van Megen, H., 227

van Poppel, P. M. J. A., 1150

Vargas, A. M., 82

Varrelmann, M., 921

Vascellum pratense, on bentgrass, fungicides, S199

Vegetables

—aster yellows index, control, S38

-disease management, fungi, S62

-food safety, S71

-management system, microbial communities, S76

—nematicide, evaluation, S69
Vegetation, digital image analysis, Wyoming, S28 Velazquez-Monreal, J. J., 1168

Velvet tobacco mottle virus, RdRp gene, S5

Venturia spp.

-V. inaequalis: on apple, fungicide resistance, S25, S53; on apple, genotype shift, Pennsylvania, S149; on apple, Indiana and Michigan survey, S21; benzimidazole resistance, Indiana, S106; QoI resistance, mutation, S71

-V. pirina, ascospore maturation, factors, 453

Verplancke, G., 968

Verticillium spp.: on Ailanthus, epidemiology, S195; transposable elements, S4

-V. dahliae, comparative genomics, S65; detection, soil, S12; fish emulsion effect, 274; on lettuce, California, S5; on lettuce, suppression subtractive hybridization, S65; on potato, metam-sodium, 362; race 1, analysis, S81; on spinach, seed treatments, S30; on strawberry, resistance and tolerance, $\mathrm{S} 65$

-V. longisporum, on oilseed rape, resistance: cover photo, July; and systemic spread, 802

Vettraino, A. M., 792

Vico, I., 636

Vilcinskas, A., 729

Vintal, H., 775

Viroids, pome and stone fruit, polyprobe for detection, S73

Viruses

—diagnosis, Classic Card technology, S125

- endornaviruses, detection, S113

- evolution, S165; evolution routes, S165

—Great Smoky Mountains National Park survey, S112

—resistance mechanisms, S164

-rhabdoviruses, cell interactions and insects, S153

-RNA, on miscanthus and switchgrass, method, S2

— silencing pathways, RNA directive, S164

- tobacco protein, callose, S165

-tobamovirus, in water, New Zealand forest, S194

-tospovirus, vector specificity, S153

- virus-host interaction, yeast as model, S165

Vittal, R., 1412

Vivek, B. S., 540

von Tiedeman, A., 802

Waalwijk, C., 1377

Walcott, R. R., 666

Wallhead, M. W., 957

Walnut

-bark canker, rubifacine production, genetics, 145

—cankers, Geosmithia, S37

Wang, J.-X., 1403

Wang, L., 900

Wang, M. N., 1209

Wang, N., 50

Wang, W., 1090

Wang, X., 1355

Wang, Z., 1121

Ward, P., 1273

Watermelon, multi-virus infections, Florida, S131

Webber, J., 792

Wechter, W. P., 666

Wegulo, S. N., 943

Weller, D. M., 472

Werres, S., 792

Wheat

- crown and foot rot, Idaho, S142

—dwarf bunt, species number, S8

- eyespot, resistance genes, S119

-Fusarium asiaticum and F. graminearum, sterol demethylation inhibitor resistance, China, 487

-Fusarium crown rot: inoculation method, S103; seedling resistance, $\mathrm{S} 185$; tolerance, $\mathrm{S} 121$ 
-Fusarium crown rot and root rot, Montana, S89

-Fusarium head blight: cultivar and deoxynivalenol, S53; deoxynivalenol, 759; deoxynivanenol, models, S94; deoxynivalenol, postanthesis moisture, 320; deoxynivanenol, symptom association, S96; humidity and rain, S67 management in Missouri, S126; moisture and doxynivalenol, S159; random-coefficient mixed models, 850; resistance, S159; trait locus mapping, emmer, 447; weather variables, S67

-Fusarium head blight and damaged kernals, S139

-Fusarium spp., PCR optimization, S103

-head scab, identification, S118

-leaf rust: aggressiveness components, 869; dispersal in canopy, 1216

genotype and phenotype differentiation, 750

-leaf and stripe rust, mapping, S25

-powdery mildew: genetic analysis, UK and Israel, 840; resistance and quantitative trait loci, 1121

- powdery mildew and leaf rust, spatiotemporal dynamics, geostatistical analysis, 974

-resistance, broad-spectrum, S49

- spot blotch and tan spot, seeding time, S48

-Stagonospora nodorum blotch, Tsn1-ToxA interaction, 906

-stem rust: microsatellite markers, 282

resistance, S97; Ug99, resistance, S199

-stripe rust: disease progress curve and genetics, 1265; durable resistance, genetics, 968; incompatible genes, S138; models, S118; novel resistance genes, S56, S72, S137,1209; oxygen species and peroxidase, S138; resistance, S125; strain aggressiveness, 89

-take-all: biocontrol, S55; 2,4-diacetylphloroglucinol sensitivity, 472; endophytic bacteria, S55; epidemiological analysis, 861 ; glucanase secretion, S148

- $\tan$ spot: Mazandaran, S35; resistance, genomics, S120

—virus survey, Great Plains, S105

-yellow dwarf, Alabama, S15

Wheat streak mosaic virus

—alternate hosts, Great Plains, S57

- genotyping, S110

— severity trends, S143 -virus titer growth, water, S105

-yield and space approach, 432

Whistler, C. A., 679

Whitaker, B. D., 636

Whitfield, A. E., 404

Wicklow, D. T., 109

Widholm, J. M., 1412

Widmer, T. L., 792

Willocquet, L., 930

Windstam, S. T., 1258

Winton, L. M., 739

Wllis, D. K., 404

Woods, D. M., 67

Workneh, F., 432

Wraight, S. P., 1421

Wu, Y.-L., 1312

Wulff, N. A., 301

Wylie, S. J., 512

Xanthomonas spp., on rose, azibenzolar-S-methyl, S133

-X. albilineans, on sugarcane, membrane protein, S110

-X. arboricola, on peach and nectarine, oxytetracycline and copper resistance, $\mathrm{S} 82$

$-X$. axonopodis: on anthurium, field screening, S63; on bean, PCR assay for detection, S34; on cassava, diversity in Colombia, S130; on citrus, biofilm and motility, S56; in citrus, pectate lyase homolog, S73; on citrus, survival gene, S48; copper tolerance, analysis, S198; on soybean, motility and virulence genes, S5; on soybean, race 3 protein genes, S104; on soybean, virulence specificity, 996

$-X$. campestris: on bell pepper, quinoxyfen and acibenzolar-s-methyl, S114; biofilm and DSF signalling, S154; flower and seed infection, S134; on umbelliferous seed crops, Oregon, S84

-X.citri, on citrus: copper and streptomycin treatment, S10; eradication, 1370

$-X$. hortorum, on carrot, detection, S186

$-X$. oryzae: diagnostic marker, genomics, S69; on rice, virulence and mutation, $\mathrm{S} 146$

-X. perforans, on tomato, race T3, hypersensitivity, 1037

-X. translucens, on wheat, resistance, S2
-X. vesicatoria, biofilm, Salmonella synergism, S51

Xia, X., 1121

Xiao, C. L., 532

Xu, J.-Q., 1403

$\mathrm{Xu}, \mathrm{X} ., 900$

Xylella fastidiosa

—on almond, phage, S22

-biofilm formation, mineral effect, S27

-on blueberry: genetic distinction, S93; Georgia and Florida, S170; nutrition, S2

-on Chitalpa tashkentensis, genetics, S107

-fluorescent markers, S33

-on grape: polygalacturonase, S138; regulation,

S4; in sharpshooter, S6; xylem sap protein, S74

- on oleander, PCR for detection, S55

-on pecan: insect transmission, S83; vectors, S114

- phytoreovirus, vector, S124

- vector transmission, models, S155

Yamamoto, M., 369

Yan, J., 1121

Yeater, K. M., 1078

Yeh, H.-H., 812

Yeh, S.-D., 1312

Yellow dwarf virus, vector and proteins, S153

Yermiahu, U., 557

Yi, S. H., 721

Yin, Y., 487

Yu, J.-J., 1403

Yu, T., 258

Yuen, J. E., 782

Yuen, J. M. F., 1070

Yvon, M., 265, 632

Zala, M., 1090

Zapata, M., 1070

Zea mays (see also Corn, Maize)

-PR10 proteins, S202

- stolbur phytoplasma, Reptalus panzeri transmission, 1053

- storage molds, Cuba, S190

Zeller, K., 390

Zoysiagrass, foliar disease, cause, S128

Zygophiala spp., on apple, flyspeck association, China, S71 


\section{Author Index for APS Annual, Special Sessions, and Division Meeting Presentations}

Abad, Z., S37, S118

Abawi, G. S., S194

Abbas, H. K., S1, S99

Abbasi, P. A., S1

Abbott, P., S191

Abdelnabby, H. M., S85

Abel, C. A., S1

Abou Ghanem-Sabanadzovic,

N., S112, S112, S112, S112,

S112, S112, S113

Abou Haidar, C., S111

Abril, M., S178

Abu-El Samen, F., S64, S65

Acevedo, M., S1, S14

Achor, D. S., S52

Acosta-Leal, R., S1

Adams, G. C., S130, S130

Adams-Phillips, L. C., S16

Adaskaveg, J., S23, S35, S36, S36, S145, S181

Adhikari, T. B., S2, S2, S18, S48, S49,S101, S101

Adkins, S., S71, S131, S139, S171

Aegerter, B. J., S180

Agarkova, I. V., S104

Agindotan, B. O., S2

Agnello, A., S191

Agudelo, P., S200

Aguilar-Perez, L. A., S93

Aguilar-Sánchez, N. C., S89

Ahmed, M., S2

Ahonsi, M. O., S2

Aime, M., S88, S138, S196, S201

Ainsworth, T., S26

Akhoundi, F., S2

Alabi, O. J., S2, S3, S68, S125

Alarcon, P. A., S53

Alcantara, T. P., S123

Aldamrat, R., S44

Aldwinckle, H., S63, S191, S191

Alexander, K., S128

Ali, S., S2, S2, S49, S94

Alizadeh, A., S79

Allaghehband Zadeh, N., S113

Allen, C., S57, S166

Allen, R. W., S110

Allen, T. W., S98, S112

Almandoz, J. E., S188

Almeida, R. P., S130, S155

Almeyda, C. V., S3

Altier, N. A., S102

Altinparmak, S., S9

Alvarado, V., S3, S140

Alvarez, A., S68, S80, S99, S101, S101, S115

Amaike, S., S159

Amaradasa, B. S., S3

Amarante, C. V., S133

Ambrósio, A. B., S40

Amedeo, P., S42

Ames, K. A., S15

Amiri, A., S3, S3

Amyotte, S., S4, S65

Anchieta, A., S65, S65

Anco, D. J., S4

Ancona, V., S4

Anders, M., S17

Anderson, A., S183

Anderson, J. L., S29

Anderson, R., S164, S167

Andrade-Piedra, J. L., S8

Angel, C. A., S4

Angelov, L., S13
Antonopoulos, D., S4, S4

Antony, G., S5

Antoun, H., S11

Appel, J., S63

Ardales, E., S17

Arellano, C., S10

Arias, C., S201

Arie, T., S124

Ariss, J. J., S128

Armas, R., S189

Armengol, J., S8

Armentrout, R. S., S20

Armstrong, D., S50

Arquero, O., S88

Arredondo, F., S164, S167

Arroyo, C. J., S108

Arsenault-Labrecque, G., S192

Arthur, K., S5

Ashikaga, T., S26

Askew, A., S33

Atakan, E., S62

Atallah, Z. K., S5, S43, S81

Athinuwat, D., S5, S104

Atkins, S., S189

Attanayake, R. N., S5

Augusto, J., S5, S16, S196

Austin, C. N., S6

Austin, G. D., S32

Avenot, H., S6

Avila, L., S6, S40

Avis, T. J., S11

Aylor, D. E., S191

Aysan, Y., S62

Azevedo, M., S50

Babadoost, M., S6

Babiker, E., S6, S180

Babujee, L., S57, S166

Backman, P. A., S83, S83, S159, S204

Backus, E. A., S6, S124

Bacon, C. W., S7, S99

Bae, H., S73, S203

Bag, S., S7, S7, S7

Bai, J., S2

Bailey, B. A., S83, S83, S203, S204

Baker, K., S7

Baker, S., S42

Bakker, M. G., S7

Bakkeren, G., S116

Balbach, H. E., S8

Baldo, A., S191

Baldwin, T. T., S8

Balint-Kurti, P., S10

Baloglu, S., S62

Ban, J., S194

Banihashemi, Z., S8

Banowetz, G., S50

Bao, L., S164

Bao, X., S8

Barak, J., S51, S178

Barari, H., S35

Barceló, M., S189

Bargeron, C., S175

Barnes, A., S126

Barney, W., S128

Barona, D., S8

Barros, G., S88

Barthe, G., S30

Bartnicki, V. A., S133

Bartz, F. E., S57

Bartz, J. A., S8

Bassett, C. L., S14, S191

Bastas, K., S9

Bateman, A., S1, S14
Batuman, O., S9, S68

Batzer, J., S71, S102

Baughman, T. A., S201

Baum, T. J., S116, S145, S164

Baumgartner, K., S9, S108

Bayman, P., S166

Baysal-Gurel, F., S9, S9

Bean, S. R., S94

Beattie, G. A., S9

Beck, H., S53

Becker, C., S177

Becker, E., S10

Becker, J. O., S139, S161

Beckerman, J., S21, S106

Been, T. H., S158

Beerepoot, A. J., S143

Behlau, F., S10

Beladi Behbehani, S., S10

Bélanger, R., S46, S192, S192

Belcher, A., S10

Beligan, G., S17

Bell, A. A., S82, S168

Beltrán-García, M., S79

Bender, C. L., S168

Bender, G., S102

Benitez, M., S10

Bennett, C., S91

Bennett, M., S145

Bennett, R. S., S10

Benson, D., S97, S122

Benson, J., S180

Bent, A., S16, S126

Benyon, L., S11

Berestecky, J. M., S101, S101

Berg, R. K., S22

Bergemann, S., S9

Berger, P., S172

Bergstrom, G. C., S143

Berkett, L. P., S26

Bernal, A., S40, S120, S130, S188

Berner, D. K., S14, S203

Bernier-English, V., S11

Berruyer, R., S167

Berube, J. A., S11

Bespalhok Filho, J. C., S111

Besterman, J. M., S24

Bestor, N. R., S11

Bezerra, J., S11, S77

Bhat, R., S11

Bhatnagar, D., S42

Bhatt, J. C., S19

Bhavani, S., S120

Bi, Y., S77

Bicici, M., S62

Bienapfl, J. C., S12

Bihon, W., S12

Bilodeau, G. J., S12

Birch, P., S27

Birkebak, J. M., S44

Birren, B., S65

Bittel, P., S126

Blackmoore, M., S12, S100

Blackwelder, T., S44

Blades, B. S., S61, S103

Blair, M., S86

Blaisedell, B., S12, S41

Blanchette, R. A., S102

Blanco, L., S188

Bleakley, B. H., S12

Block, C. C., S13, S34, S119

Bloomberg, J. R., S36, S91

Bluhm, B., S153

Blum, M., S169

Blunt, T., S13, S105

Boal, R. J., S187

Bobev, S., S13

Bock, C. H., S13, S13

Bockelman, H., S14

Bockus, W., S48

Bocsanczy, A., S14

Boehm, M., S66, S107, S115

Bohning, M., S64

Bohra, D. L., S14

Boland, G. J., S16, S97

Bolda, M., S18

Boller, T., S126

Bollmann, S., S14

Bolton, M., S14

Bond, J., S37, S53, S113

Bonde, M. R., S14

Bonello, P., S92

Bonifacio, A., S134

Bonman, J., S1, S2, S14, S49

Boozer, R., S24

Borejsza-Wysocka, E., S191, S191

Bornt, C. H., S91

Borrego, J. G., S190

Borth, W. B., S118, S125

Bosco, D., S130

Bosland, P. W., S88

Bostock, R., S23, S102, S145, S172

Boston, R., S54

Bottner, K. D., S70

Botts, M., S15

Boule, J., S119

Bounds, R., S177, S180, S181

Bowden, R., S31, S38, S93

Bowen, K., S15, S49, S50, S132, S201, S201

Bowness, R., S21

Boyette, C. D., S139

Boyette, D. C., S58

Boyjigitov, F. M., S80

Boykin, D., S72

Bradeen, J. M., S15

Bradford, C. S., II, S167

Bradley, C. A., S2, S15

Brady, J. A., S33

Bragard, C., S15, S84

Bragg, J. N., S39, S73

Branch, W., S197

Brannen, P., S3, S93, S170

Brantner, J. R., S15

Brar, H., S167

Brasier, C., S162

Bratcher, A., S24

Braun, S. E., S16

Brenneman, T., S5, S16, S96, S196, S196, S200

Bretting, P., S64

Brewer, J. R., S203

Brière, S., S193

Briggs, A. G., S16

Brissey, L. M., S30

Britt, J., S16, S16

Brlansky, R., S45, S52, S111 
Brown-Guedira, G., S25

Browning, M., S205

Bruckart, W. L., S33, S175, S203, S203

Brule-Babel, A. L., S41

Bruns, D., S32

Bruns, H. A., S1

Brust, G., S125

Buchenauer, H., S138, S148

Buchman, J. L., S117

Buck, J., S94, S116, S196

Budowle, B., S160

Buell, C., S69

Bula, K., S47

Bulluck, R., S102, S172, S172

Buol, G. S., S129

Burans, J., S160

Burbano, C., S40

Burbano-Figueroa, O., S17

Burgess, T., S12

Burgos, M., S17

Burke, I. C., S6

Burlakoti, P., S18

Burlakoti, R. R., S18

Burnett, A., S68, S193

Burns, J., S36

Burpee, L., S94

Burr, T. J., S5, S104

Burrell, D., S198

Burrows, M. E., S57, S105

Buruchara, R. A., S90

Busby, R. R., S28

Butler, D. M., S18

Butler, E. L., S129

Butler, J., S173

Byamukama, E., S18

Cabrera, D., S188

Cadle-Davidson, L., S89

Cai, G., S18

Cai, H., S143

Cai, L., S28

Calderon, C., S122

Calderon, F. J., S18

Calvo, A. M., S152

Camacho-López, M. D., S40

Camberato, J. J., S80

Camilli, K., S91

Camilo, F. R., S25

Camp, M. J., S135

Campanella, D. M., S19

Campbell, B., S125

Campbell, H. L., S50, S50

Campbell, K., S103, S103

Capelluto, D., S167

Capote, E., S188

Carbone, I., S88, S127, S201

Cardenas, M., S40, S120

Cardwell, K., S172, S176

Carnes, M., S107

Carpenter, D., S128

Carras, M. M., S205

Carrillo, M. C., S19

Carrillo-Madrigal, H., S79

Carrillo-Medrano, S. H., S97, S97

Carrington, J., S14, S164

Carris, L. M., S8

Carroll, A. M., S81, S204

Carroll, J., S191

Carta, L. K., S85

Carter, L. L., S143

Cartwright, R. D., S19

Carver, J., S110

Cary, T. J., S28

Castañeda, M., S190

Castaneda-Gill, J. M., S33

Castell-Miller, C. V., S19

Castello, J. D., S194
Castillo, J. D., S196

Castlebury, L. A., S44

Castrillo, L. A., S16

Castroagudin, V. L., S19

Caswell-Chen, E., S147

Catal, M., S130, S130

Cating, R. A., S19, S19

Catlett, S. M., S20, S197

Cattaneo, M. G., S201

Cavanagh, J., S108

Cavin, C. A., S203

Cavinder, B., S20

Cepero de Garcia, M. C., S40

Ceresini, P., S166

Cha, J., S146

Chacón, O., S188

Chai, W., S3

Chaijuckam, P., S20, S20

Chain, F., S192

Champoiseau, P. G., S20

Chan, L., S136

Chanda, A. K., S20, S197

Chanda, B., S20

Chandrasekar, S., S21

Chang, C., S2, S93, S170

Chang, H., S21

Chang, J., S21

Chang, K., S21

Chang, P., S21

Chang, S., S21

Chang, Y., S45

Changzhi, H., S164, S167

Chao, S., S49

Chapala, M. M., S201

Chapman, K., S21, S106

Charbaut, T., S85

Charkowski, A., S47, S97, S167

Charlton, B. A., S158

Charlton, N. D., S22

Charudattan, R., S172

Chase, T. E., S22

Chastagner, G. A., S45, S180, S181

Chaudhary, M., S22

Chein, R., S21

Chekali, S., S41

Chellemi, D. O., S173

Chen, C., S9, S22, S73, S74, S151

Chen, H., S143

Chen, J., S22, S28

Chen, K., S21

Chen, L., S22, S26, S140

Chen, S., S17, S23

Chen, W., S5, S94, S141

Chen, X., S23, S29, S56, S72, S75, S78, S111, S118, S137, S137, S138

Chen, Y., S22, S50

Chen, Z., S20, S65, S74, S92. S99, S144, S197, S202

Cheng, D., S74

Cheng, P., S23

Cheng, Y., S138

Cherifi, F., S88

Chilvers, M. I., S75

Chitrampalam, P., S23

Chiu, C., S23

Cho, J., S146

Chong, J., S1

Chowdhury, M. R., S131

Christiano, R. S., S23

Christopher, D., S104

Chulze, S. N., S88

Chungath, V. J., S129

Ciftci, M. A., S62

Citovsky, V., S165

Civerolo, E. L., S73

Clark, A. J., S83
Clark, D., S53

Clarke, B. B., S109, S195

Cleveland, T., S42, S92, S202

Clough, S. J., S106

Coats, K., S181

Cobine, P., S27

Cochran, A., S23, S36, S181

Cochran, K. A., S197

Cogal, A. G., S82

Cohen, Y., S169

Coker, C. M., S98

Colbert, S., S42

Colcha, E., S8

Coleman, C., S134

Coltman, R., S47

Colucci, S., S171

Comstock, J. C., S44

Condon, B., S149

Coneva, E., S24

Conn, K. L., S24

Connell, J. H., S35, S36

Connell, L., S24

Conway, K., S17

Conway, W. S., S135

Cook, A. Z., S13

Cook, F., S84

Cooke, L. R., S130, S130

Cooley, D. R., S191, S192

Coombs, J., S65

Coop, L., S24, S174, S181,

S181, S182, S184, S185

Cooper, B., S49

Cooper, G. T., S24

Cooper, K., S164

Copes, W. E., S24

Coram, T., S25

Corley, J., S128

Coronado, M. F., S188

Correll, J. C., S19, S156

Cortez, A. A., S142

Costa, J. C., S25

Costadone, L., S25, S182

Cota, L. V., S25

Cotty, P. J., S40, S47, S58, S82, S98, S158

Coutinho, T., S27, S58

Cox, K. D., S111, S135

Cox, K. M., S25

Craig, J. P., S76

Crane, J., S102

Cranshaw, W., S37, S128, S133

Craven, K. D., S22, S43

Creamer, R., S90, S170

Cregan, P., S25

Crespo, J., S188

Creswell, T., S143

Crockford, A., S47

Cromwell, M. L., S26

Crossa, J., S120

Crosslin, J. M., S117, S187

Crump, A., S26

Crutcher, F. K., S26

Cruz, A. T., S190

Cruz, C., S188

Cruz, D. A., S26

Cruz, M., S188

Csinos, A., S26, S57, S67, S137, S197, S198

Cubeta, M. A., S57, S166

Culbreath, A., S73, S196, S197

Cunningham, B., S136

Cuomo, C., S65

Cuppels, D. A., S26

Curtis, M., S117

Cutulle, M. A., S26

Cyr, P., S64

Czajkowski, R., S27

Czymmek, K., S167

D’Amore, D. V., S52

da Graca, J., S157

Daane, K. M., S130

Daleo, G. R., S34, S34

Daly, C., S181, S181, S182, S184

Damann, K. E., S27, S126

Damayanti, T., S125

Damicone, J. P., S101, S129

Damsteegt, V. D., S104, S205

Danchok, R., S122

Darby, H. M., S26

Dardick, C. D., S14

Daros, E., S111

Dart, N. L., S180, S181

Datnoff, L. E., S55, S56

Daughtrey, M., S16, S192

Daugovish, O., S18

Davelos-Baines, A. L., S123

David, N., S158, S183

Davies, L. R., S47

Davis, D. D., S195

Davis, E. L., S116, S145

Davis, J. R., S181

Davis, M., S76, S81, S150

Davis, R. E., S139, S143

Davis, R. M., S5, S10, S20, S20

Davis, R., S180

Davis, T. M., S135, S135

Dawes, S. M., S32

Day, B., S172

De Boer, S. H., S32

de Carvalho, R. C., S111

de Figueiredo, P., S4

de Jonge, R., S65

De La Fuente, L., S27

De La Torre, C., S27

de Maayer, P., S27

de Sá, P. B., S27, S200

de Souto, E. R., S111

de Souza, J. T., S77

de Souza, S. R., S111

De Wolf, E., S31, S93, S94, S173

Dean, R., S42, S166

DeBauw, A., S180

del Rio Mendoza, L. E., S92, S105

del Rio, L. E., S18, S58

del Río, M., S133

Dela Paz, M., S17

Delgado, M., S189

Demers, J., S28

Deng, C., S118

Deng, M., S39

Deng, X., S28, S156 
Ding, H., S61

Ding, K., S61

Ding, S., S29, S146

Dinkins, R. D., S126

Dixon, L. J., S44

Dixon, R. A., S132

Dixon, W., S172

Dobinson, K. F., S4, S65, S80

Dobson, A., S124

Doddapaneni, H., S73, S74

Dodge, S. C., S205

Dogra, S., S5

Dolezal, A., S42

Dolezal, W., S198

Dolja, V. V., S61, S103, S165

Domier, L. L., S2, S60, S128

Dominguez, M., S188

Dominguez-Alvarez, J. L., S110

Donahoo, R. S., S29, S67

Dong, J., S150

Dong, Y., S29, S84

Donofrio, N. M., S68, S81, S204, S204

Dorrance, A. E., S32, S164

Dossey, S. M., S29

Doster, M. A., S85

Dotson, P., S20

Dou, D., S164, S167

Douce, G. K., S175

Douches, D., S64, S65, S130, S130

Dragila, M. I., S96

Draper, M., S102, S172

Driever, G. F., S89

Druffel, K., S3, S7, S29, S31, S49, S74, S85

Dry, I. B., S89

du Toit, L., S5, S30

Duan, Y., S11, S61, S73, S74, S133, S157

Duarte, I., S30

DuBose, V., S62, S63

Dugan, F. M., S5, S30

Duncan, K. F., S44

Dung, J. K., S30, S182

Dunkle, R., S156

Durham, B. P., S28

Durrin, J. S., S30

Dutt, M., S30

Dutta, B., S198

Duveiller, E., S48, S120

Duy, J., S24

Dyer, A., S89

Eckhardt, L. G., S148

Eddy, R., S31, S93

Edmonds, R., S71, S105

Edwards, J. T., S60

Edwards, M. C., S31

Egel, D. S., S82

Eggenberger, A. L., S50

Egorov, T., S175

Ehret, G. R., S82

Eid, S., S31

Eigenbrode, S. D., S61

Eikemo, H., S124

Ekramoddoullah, A., S75, S94

El Mounadi, K., S31, S31

Elateek, S. Y., S31

El-Habbak, M. H., S32

Elling, A. A., S164

Elliott, C. R., S32, S32

Elliott, G. C., S193

Elliott, J. L., S88

Elliott, M., S32

Ellis, M. A., S4

Ellis, M. L., S32

El-Lissy, O., S172

Elmer, W. H., S55, S192
Emberland, G., S64

Endes, A., S62

Enebak, S. A., S199, S200

Engels, R., S65

English, J. T., S46

Epstein, L., S134

Erginbas, G., S103

Esgar, R. W., S85

Eskalen, A., S33, S81, S102

Eskandari, F., S33, S104, S203

Esker, P., S56, S59, S59, S162, S174

Esquivel, J. F., S82

Esteves, I., S189

Estevez de Jensen, C., S110

Estevez, C. A., S135

Ethredge, W. J., S199

Eujayl, I. A., S125

Evans, C., S164

Evans, G., S102

Evans, T. A., S68

Eveillard, H., S85

Everhart, S. E., S33

Eversole, K., S177

Everts, K., S63, S144, S151, S205

Faber, B., S102

Fahlgren, N., S14

Fairbanks, D., S134

Fakhoury, A. M., S31, S37, S92, S113

Fan, Z., S138

Fang, Z. D., S46

Farnsworth, J. L., S33, S42

Farokhi Nejad, R., S113, S113

Farrar, J., S34, S182

Farrell, R. E., S191

Farrokhi Nejad, R., S113

Faske, J., S33

Feau, N., S51

Fedorova, N., S42, S166

Fei, F., S138

Feibert, E., S43

Feliciano-Rivera, M., S33

Fellers, J., S25, S116

Felts, D., S89

Feng, X., S146

Ferguson, L., S34

Fernández, A., S188

Fernandez, M. B., S34, S34

Fernández, P., S134

Fernando, D., S41

Ferrandino, F. J., S13, S191, S192

Ferreira, A., S164, S167

Ferreira, M. A., S127

Ferrin, D. M., S123

Ferry, A., S34

Fessehaie, A., S34, S34

Fiallo, E., S190

Fiallo-Olive, E., S189

Fiallos, F., S40

Fichtner, E. J., S35

Fiedler, K. D., S192

Fieland, V., S47, S100

Filiatrault, M. J., S163

Fitch, M., S63

Flaherty, J. E., S20, S197

Flanders, J. T., S199

Flanders, K., S49

Fleites, L., S110

Fletcher, J., S110, S110, S139, S159

Flores, F., S35

Floyd, C., S78

Fofanah, F., S90, S90

Fonné, R., S169

Foote, P., S125
Forbes, G., S8, S122

Forge, T., S35, S43

Foroutan, A., S35, S35, S35, $\mathrm{S} 35, \mathrm{~S} 35, \mathrm{~S} 35$

Forsline, P. L., S60

Forster, H., S23, S35, S36, S36, S181

Fortunato, A. A., S36

Fought, L., S36, S91, S177

Fouly, H., S36

Fox, A., S24, S174, S181, S181, S182, S184, S185

Fox, G. M., S194, S194

Fraedrich, S., S102

Fraley, C., S84

Franc, G., S105

Francis, M., S36, S30

Franco, L., S189

Franco, T., S64

Franco, Y., S188

Franco-Lara, L., S36, S37, S39

Frank, M., S37

Frantz, J. M., S76

Fravel, D. R., S175

Freeland, E., S37

Freeman, B. C., S9

Freitas-Astua, J., S96

French, J. M., S37, S107

French, R. C., S127

French-Monar, R. D., S37

Friesen, T. L., S77

Fritschi, F., S74

Frohning, C., S37

Frost, K. E., S38, S38

Fry, W. E., S18

Fu, D., S38

Fu, Y., S146

Fuchs, M., S96

Fuentes-Bueno, I., S38

Fuerst, G. S., S167

Fujiyoshi, P., S9

Fukui, R., S139

Fuqua, C., S154

Gabriel, D. W., S38, S110

Gadoury, D. M., S89, S124

Galagan, J., S65

Gale, L. R., S55

Gáll, J. M., S54

Gallegos, L. L., S182

Gallup, C. A., S39

Galvez, E. J., S39

Ganesan, U., S39

Ganske, D., S41, S42

Gao, Q., S20, S39, S79

Gao, X., S39

Garavito, M. F., S39

Garbelotto, M., S92

Garber, N. P., S40

Garces, F. F., S40, S40

Garcia Pedrajas, M. D., S65

Garcia, L., S39, S40

García, O., S40

Garcia-Velasco, R., S40

Gardner, C., S64

Gargouri, S., S41

Garibaldi, A., S41, S129

Garrett, K., S122, S147, S161

Garrett, W. M., S68

Garrison, M., S41

Garton, J. E., S198

Garzon, C. D., S35

Gassmann, W., S165

Gatch, E., S30

Gates, C. D., S28

Gautam, P., S159

Gauthier, V. M., S41

Geary, B., S12, S41, S134, S180, S184

Gebhart, D. L., S28

Geddens, R., S41, S42, S42

Genger, R. K., S97

Gent, D. H., S33, S42, S75, S171, S174

Gent, D., S24, S87, S174, S182, S184, S185

Genzlinger, L., S198

Georgianna, D., S42

Gerberich, K. M., S197

Gerhardt, D., S97

Gerik, J. S., S10

German, T., S153

Gessler, C., S42

Gevens, A. J., S59, S198

Ghabrial, S., S27, S32, S38

Ghadamyari, S., S42, S89

Ghaderi, M., S43

Gharbi, M. S., S41

Ghimire, S. R., S22, S43, S54

Gibbs, A. J., S43

Giesler, L. J., S43

Gigot, J., S43

Gijzen, M., S80

Gil, S., S83, S114

Gilbert, B. M., S167

Gilbertson, R., S9, S22, S68, S131, S142

Gildow, F., S153

Gilliland, S., S139

Gil-Vega, K. K., S51

Giraldo, M. C., S167

Giroux, G., S192

Girsova, N., S98

Gisi, U., S169, S169, S169

Gitaitis, R., S93, S137, S198, S200

Givens, D. R., S45

Glasner, J. D., S163

Glawe, D., S5, S43, S44, S71, S105

Gleason, M., S71, S102

Glenn, A. E., S8, S44, S99

Glynn, N. C., S44

Goates, B., S14, S44

Godoy da Silva, A., S88

Goedeke, L. A., S204

Goheen, E., S61, S61

Gold, S., S4, S65, S178

Goldberg, N. P., S37, S107

Golino, D. A., S44, S44

Golod, J., S176

Gómez, G., S189

Gomez, H., S117

Gomez, J. M., S118

Gongora, C., S45

Gonsalves, D., S63

Gonzalez, C. F., S30 
Grabowski, M., S46

Graham, J., S10, S13, S30, S36, S46, S57

Graham, T., S107

Grajales, A., S40, S120

Gramacho, K. P., S77

Granke, L., S46, S142

Grant, S. J., S80

Grau, C. R., S56

Graves, A., S133

Gray, M. E., S2

Gray, S., S83, S141, S153

Grazzini, R., S119, S119

Green, L., S99

Green, T., S191

Greer, A., S98

Greer, C. A., S20

Grégoire, C., S46, S192

Griffey, C. A., S204

Griffin, J., S63

Griffin, T., S69

Griffiths, P., S100

Grisham, M. P., S46

Groom, T., S174

Grosic, S., S167

Gross, D. C., S141

Gross, N. W., S46

Gross, P., S47

Grosser, J., S30

Grove, G., S6, S25, S33, S75,

S181, S182, S182, S182, S184, S185

Groves, C. L., S38, S38

Groves, R., S38, S38 S47, S95

Gruber, B. R., S47

Grubisha, L. C., S47

Grunwald, N., S14, S32, S32, S45, S47, S100, S175

Gu, B., S164, S167

Gu, G., S47, S76

Guaragna, M., S59

Guarino, L., S64

Guateque, A., S37

Gubler, D., S108, S182, S184, S186

Gubler, W., S182, S183, S186, S186

Gudmestad, N., S2, S52, S140

Guerrero-Herrera, M. D., S98

Guevara, M. G., S34, S34

Gugino, B. K., S144, S194

Gulati-Sakhuja, A., S142

Gullino, M., S41, S129

Gulya, T. J., S13

Gundersen, B., S57, S104, S183

Guo, B. Z., S73

Guo, H., S22, S28

Guo, J., S61, S140, S146, S146

Guo, L., S48, S48, S151

Guo, Y., S48

Gupta, V., S48

Gurung, S., S2, S2, S48, S48, S49

Gutha, L. R., S49

Gutierrez, D., S134

Guttieri, M., S72, S96

Gutting, H. C., S142

Guzman, M., S36, S37, S189

Guzmán-González, S., S79

Gwinn, K., S72

Gyawali, S., S18, S49, S49

Hackett, W. P., S17

Hadi, B. A., S49

Hadwiger, L. A., S49, S49

Hafner, R., S47

Hagan, A. K., S50, S50

Hajimorad, M. R., S50

Hajimorad, R., S131
Hajmansoor, S., S60

Halbert, S., S107

Halbrendt, J. M., S85

Halgren, A., S50

Hall, C., S174

Hall, D., S11, S133, S187

Hallen, H., S20

Halley, S., S12

Halloran, J., S69, S96

Halterman, D., S50, S168

Ham, J., S62, S83

Hamelin, R. C., S51, S64

Hamilton, J., S69

Hamlin, J., S122

Hamm, P., S57, S158, S158, S183

Hammami, W., S192

Hammerschmidt, R., S84, S89, S148, S172

Hammes, G., S42

Hammond, J., S73

Hammond, R. W., S51, S67

Han, C., S72, S144, S149

Han, D., S56

Han, Q., S55, S138, S138, S148, S150

Han, S., S183

Hanagriff, R., S120

Hanlon, R., S164, S167

Hanna, J. W., S65

Hanna, L., S111

Hanna, R., S68

Hansen, E. M., S61

Hansen, E., S15, S16, S16, S47, S61, S90, S107, S122, S162

Hansen, J., S65

Hanson, B. D., S10

Hanson, L., S18, S92

Hanson, S. F., S51, S51, S107

Hanula, J., S102

Hao, J., S77, S84, S148

Hao, L., S51

Hao, W., S54, S145

Harbertson, E., S75

Harlan, B., S137

Harmon, C., S51, S59, S102, S135

Harmon, P., S24, S51, S59, S61, S135, S143

Harrington, T., S102

Harrison, N. A., S70

Harrison, W. E., S199

Hartman, G., S21, S77, S115, S136

Hartney, S. L., S52

Hartung, J., S52, S95, S157

Harveson, R., S52, S52

Hassell, R., S63, S128, S151

Haudenshield, J. S., S115

Hausbeck, M., S46, S89, S106, S137, S142, S142, S172

Havens, W. M., S27

Hawes, M. C., S140

Hay, F., S174

Hayes, A. J., S71

Hayes, R., S5, S65, S107, S168

Haynes, K. G., S138

He, Y., S34

He, Z., S69, S96

Heber, S., S165

Hed, B. E., S193

Hedberg, J., S175

Heerema, R. J., S37

Heidenreich, C., S124

Heiman, D. I., S65

Hein, G. L., S43

Hell, K., S88

Hellier, B. C., S30

Henderson, L. A., S142
Henkels, M. D., S106

Henn, A., S112

Henne, D., S52

Hennon, P. E., S52

Henriquez, J. L., S53, S108

Henry, B. R., S85

Henslee, K. A., S32

Herath, P., S53

Hermann, D., S169

Hernandez Nopsa, J., S53, S139

Hernández, C., S189

Hernandez, J., S125

Hernández, R., S188

Herrera, L., S188

Herrera-Foessel, S. A., S53, S120

Herron, C., S161

Hert, A., S171

Herzog, C., S53

Hesse, U., S126

Heuchelin, S., S135

Hickman, L., S26, S197

Hicks, T. E., S66

Hidalgo, L., S189

Hildebrand, D., S39

Hilf, M. E., S71

Hill, J., S13, S50

Hillman, B., S12, S18, S98, S100

Hillnhuetter, C., S53

Himmel, P., S155, S177

Hinton, D. M., S7

Hinze, B., S121

Hirsch, P., S189

Hladky, L. L., S142, S142

Hoagland, R. E., S58, S139

Hoch, H. C., S46, S142

Hodges, A., S53

Hoenisch, R., S53

Hoeschele, I., S164

Hogg, A., S89

Hogue, P., S119

Holb, I. J., S33, S54, S54

Holbrook, C., S73, S197

Holguin, C., S134

Holmes, B. J., S30

Holmes, G., S171, S171, S171, S171, S171

Holmes, R., S54

Holmes, T., S32

Honeycutt, C. W., S96

Honeycutt, W., S69

Hong, C., S54, S100, S145

Honjo, H., S139

Hoogenboom, G., S96

Hooper, G., S53, S184

Hopcroft, D. H., S194

Hopkins, A., S147

Hopkins, B., S12, S41, S180

Hopkins, D. L., S54

Horevaj, P., S159

Horn, B. W., S88

Horsley, R., S49

Horvath, B., S3, S26

Horwitz, B. A., S149

Hoskins, P. S., S54

Hoy, J., S40

Hoying, S. A., S111

Hsieh, Y., S79

Hsu, S., S73

$\mathrm{Hu}, \mathrm{C} ., \mathrm{S} 48$

Hu, H., S148

$\mathrm{Hu}$, J., S55, S55, S102, S118, $\mathrm{S} 125$

Hu, S., S41

Huang, B., S55

Huang, C., S27, S55, S56

Huang, G., S116, S145

Huang, H., S125

Huang, J., S21

Huang, K., S204

Huang, L., S39, S55, S55, S56,

S61, S116, S138, S138, S148, S150

Huang, Q., S55

Huang, T., S56

Huang, X., S56, S138

Huber, D., S136, S161

Hudelson, B. D., S43

Hudler, G., S172

Huerta-Espino, J., S53, S120

Huettel, R. N., S201

Hughes, G., S174

Hughes, T. J., S56

Huigens, R. W., S108

Huisman, O. C., S181

Hulbert, S., S6, S29, S147, S180

Humann, J. L., S29

Hummer, K., S64

Hunger, R., S17, S60, S110

Hunter, G. C., S102

Hunter, W. B., S124

Huo, S., S118

Hussey, R. S., S116, S145

Hutmacher, R. B., S10

Hwang, J., S109

Hwang, S., S21, S45, S56

Impullitti, A., S78

Inácio, C. A., S28, S98

Inderbitzin, P., S56

Infante, D. M., S190

Ingham, R. E., S158

Inglis, D., S57, S81, S104, S183

Ingram, D. M., S112, S113

Inguagiato, J. C., S109, S195

Irey, M., S11, S57

Isakeit, T., S37, S198

Ishiga, Y., S168

Ithal, N., S147

Ito, D., S57, S105

Ivors, K., S39, S57, S122, S162

Jabaji, S., S166

Jackson, A. O., S39

Jackson, C. A., S142

Jackson, D., S199

Jackson, E. W., S1, S14

Jackson, K., S57, S67

Jackson, T. A., S43

Jacob, A., S90, S90

Jacobi, W., S133

Jacobs, A., S58

Jacobs, J. M., S57, S166 
Jenks, B. M., S58

Jentsch, P. J., S195

Jeong, K., S146

Jeong, R., S79

Jepsen, P., S24, S174, S182, S184

Jerauld, A., S164

Jertberg, J. R., S183

Jha, A., S27

Ji, P., S57, S67, S137

Jimenez, P., S39, S122

Jimenez-Diaz, R. M., S28

Jimenez-Fernandez, D., S28

Jimenez-Gasco, M., S28, S149

Jin, H., S166

Jin, J., S149

Jin, X., S58

Jin, Y., S14, S97, S111, S111

Jinek, A., S193

Jirak, J. C., S59, S59

Jo, J., S70

Jo, Y., S21, S128

Joardar, V., S42

Jodlowska, A., S66

Johnson, A., S26

Johnson, C., S59, S100, S116, S204

Johnson, D., S12, S30, S41, S182, S182, S184

Johnson, J., S57

Johnson, K. B., S127, S186

Johnson, K. L., S59

Johnson, S. H., S197

Jolley, V. D., S12, S41

Jolley, V., S180

Jones, J. B., S10, S20

Jones, K., S147

Jones, R. W., S175

Jones, S. S., S81

Joos, D. K., S85

Jordan, R., S59

Jordan, S. A., S8, S59

Jossey, S., S60

Jung, G., S194

Jurick, W. M., S60, S135

Juzwik, J., S99

Kabbage, M., S48

Kachroo, A., S20, S38, S39, S79

Kachroo, P., S20, S39, S79

Kader, K. A., S60

Kairu, G. M., S60

Kaiser, R., S176

Kaiser, W. J., S88

Kakishima, M., S133

Kakvan, N., S60

Kale, S. D., S164, S167

Kalischuk, M., S60

Kalpana, K. C., S45

Kammerer, S., S61

Kammoun, L. G., S41

Kamo, K., S59

Kanaskie, A., S61, S61

Kaneshiro, W. S., S101

Kanetis, L., S171, S181

Kang, L., S168

Kang, S., S4, S65, S93, S99, S167

Kang, Z., S29, S39, S55, S55, S56, S61, S75, S78, S138, S138, S146, S148, S150

Kankanala, P., S167

Kantartzi, S., S53

Kao, C., S134

Karasev, A. V., S30, S61, S103, S141

Karki, H., S62

Karthikeyan, G., S125
Karuiki, G., S8

Karuppannan, M., S125

Kasapoglu, E. B., S62

Kasschau, K., S14

Kastalyeva, T., S98

Kasuya, M., S139

Kaur, S., S134

Kaushik, N., S62

Kawabe, M., S124

Kawchuk, L., S60

Kayim, M., S62, S62, S62

Kearns, M., S12, S41

Keeth, T., S62

Kegley, A., S122, S122

Keinath, A. P., S62, S63, S63, S67, S151

Keith, L., S63, S183

Keller, N. P., S159

Kelly, M. R., S71

Kema, G. H. J., S166

Kemerait, R., S143, S198, S199

Kemp, J. D., S107

Kenerley, C., S26, S152

Kennelly, M., S63

Kentaro, S., S20

Kerns, J., S66, S142

Kerry, B., S189

Khan, M., S14

Khanam, N., S63

Khang, C. H., S167

Khatibi, P., S204

Kichler, J., S198

Kidarsa, T. A., S106

Kim, H., S70

Kim, J., S64, S70, S101, S154

Kim, K., S70

Kim, M., S64, S65

Kim, S., S4, S17, S22, S70, S93, S165

Kim, T., S64, S183

Kim, W., S146

Kim, Y., S63, S150, S183

Kinard, G., S64, S73

King, J., S33, S94

King, S., S76

Kinkel, L. L., S7, S115

Kinsella, K., S193

Kinzer, K., S105

Kirk, S., S35

Kirk, W., S7, S64, S65, S84, S130, S130, S148, S170

Kirkpatrick, B. C., S85, S138, S184

Kirkpatrick, S. C., S65

Kirkpatrick, T. L., S58

Kistler, H., S84

Kitin, P., S15

Kitz, L., S184

Klassen, W., S149, S149

Kloepper, J. W., S149

Klopfenstein, N. B., S64, S65

Klosterman, S. J., S4, S5, S65, S65, S81, S168

Kluepfel, D. A., S100, S145, S185, S187

Knapp, S. J., S73

Knight, S., S70

Knudsen, G. R., S64, S65, S183

Kobayashi, D., S12, S100

Kobayashi, S., S133

Koch, C., S35

Koch, P. L., S66

Koczan, J., S66

Kodetham, G., S125

Koehrsen, M., S65

Koenig, J., S66

Koenraadt, H., S66, S66

Koike, S., S18, S156

Koivunen, M. E., S125
Kokalis-Burelle, N., S18

Kolander, T. M., S66

Kolarik, M., S37

Köller, W., S25

Kolpak, S., S122

Koltuksuz, T. A., S67

Komorowska-Jedrys, J., S192

Koné, D., S67

Kong, M., S84

Kong, P., S54, S145

Koonin, E. V., S165

Koop, A., S70

Kope, H., S51

Korban, S. S., S14

Koski, T., S13

Kosta, K., S172

Kostenyuk, I., S36

Kousik, C. S., S29, S67, S131, S139, S171

Koval, N. C., S56

Kovalskaya, N., S67

Krampis, K., S164

Krause, C. R., S76

Kriss, A. B., S67, S67

Kromina, K., S98

Krueger, W. H., S89

Kruger, E. L., S47

Krugner, R., S124

Kubota, R., S68

Kuehne, S., S191

Kuhn, P., S171, S176

Kuldau, G. A., S159

Kulshrestha, S., S20

Kumar, P. L., S3, S68, S125

Kunjeti, S. G., S68

Kunkel, D. L., S128

Kuo, Y., S68

Kurle, J. E., S66

Lacombe, S., S108

LaForest, J., S53, S175, S176

Lagudah, E. S., S53

Laguette, S., S108

LaHue, S. S., S26

Lakshman, D. K., S3, S68

Lakshman, S., S68

Lakso, A. N., S6

Lalancette, N., S68, S193

Lamb, M., S52

LaMondia, J., S193

Lamppa, R. S., S45

Landa, B. B., S28

Laney, A. G., S131

Laney, R., S33

Lang, J. M., S69

Langham, M. A. C., S176

Langston, D. B., S69, S114, S137, S198

Lannon, K. R., S39

Lapchyk, L., S39, S79

Lara-Viveros, F. M., S93

Larkin, R., S69, S96

Larsen, M., S45, S47, S136

Larsen, R., S25, S69

Lassiter, B. R., S129

Lawrence, A. M., S112, S113

Lawrence, C., S55

Lawrence, K. K., S120

Lawrence, K. S., S69, S117, S196, S199, S200

Lawson, A. B., S182

Le Strange, M., S180

Leach, J. E., S19, S69

Lea-Cox, J. D., S54, S145

Leandro, L., S29, S45, S123

Leatherman, D., S128

Lee, C., S70

Lee, I., S70, S98, S139

Lee, J., S38, S70, S70

Lee, M., S23

Lee, R., S107, S156, S160

Lee, S., S70, S70, S70, S70

Lee, Y., S38

Lefebvre, F., S46

Leggett, F., S60

Lehman, S. M., S119

LeJeune, J. T., S71

Lemay, A., S34, S70

Lemo, I., S188

Leng, Y., S70

Leon, A. L., S71

Leonberger, A., S143

Leong, T., S63

Lepo, J. E., S80

Leslie, C., S17, S133

Leslie, J. F., S38

Lesniak, K. E., S71, S82

LeStrange, M., S9, S131

Leung, H., S19

Leuth, P., S116

Leveau, J. H. J., S155

Levy, L., S75, S140

Lewandowski, D. J., S27, S71, S71, S71

Lewis Ivey, M. L., S31, S71

Lewis, C., S100

Lewis, K., S93, S136, S200

Lewis, R., S116

Li, B., S114

Li, C., S72

Li, D., S72, S144, S149

Li, G., S29

Li, H., S71, S27, S28

Li, J., S72, S118, S149, S150

Li, M., S74

Li, Q., S72, S137

Li, R., S73, S142, S144

Li, S., S32, S72, S77, S140, S167

Li, W., S71, S132, S140

Li, X., S166

Li, Y., S72, S72, S73, S87, S138

Liberti, D., S80

Liess, L., S77

Lim, H., S73, S203

Lima Neto, V. C., S111

Lin, F., S148

Lin, H., S73, S73, S74, S74, S140

Lin, L., S73

Lin, Y., S21, S74

Linder-Basso, D., S98

Lindow, S., S154

LiPuma, J., S30

Littke, W., S71 
Lopes, S., S156

Lopez Nicora, H. D., S76

López, C. E., S130

López, M. O., S189

Lorang, J. M., S167

Lorenzen, J. H., S141

Loria, R., S167

Lough, T. J., S194

Louws, F., S74, S107, S109, S173

Low, W., S59

Lozovaya, V., S77

Lu, C., S74

Lu, F., S74

Lu, S., S23, S47, S76, S77

Lu, X., S77

Lucena, C., S190

Ludwig, J. W., S194

Ludy, R., S84

Luis, C. A., S133

Lujan, P., S77

Luo, C., S74

Luo, Y., S77

Lupien, S. L., S30

Luu, V. P., S101

Luz, E. M., S11, S77

Lygin, A., S77

Lynch, N., S78

Lynch, S. C., S81

M'tat, I., S41

Ma, J., S56, S78, S137, S138

Ma, L., S4, S65, S78

$\mathrm{Ma}, \mathrm{Z} ., \mathrm{S} 82$

Maccree, M. M., S145

MacDonald, J., S178

Macedo, P. E., S25

MacGregor, T., S24

MacGuidwin, A., S158

Machida, M., S42

Mackay, M., S64

MacKenzie, S. J., S78

Macknicki, C., S109

MacRae, I. V., S108

Madden, L., S4, S66, S67, S67, S72, S96, S94, S161, S161, S174

Maffei, H., S65

Maffia, L. A., S25

Magalhães, D. A., S11, S77

Mahaffee, W., S24, S115, S136, S136, S174, S181, S182, S182, S184, S185

Mahmoudi, B., S10, S113, S113, S113

Mai, P., S57

Maia, G. S., S198

Maiti, R., S42

Malapi-Nelson, M., S78

Maleki, M., S2

Maleme, H. M., S121

Mallik, I., S140

Malnoy, M., S191

Malvick, D., S12, S66, S78

Manabayeva, S. A., S79

Mandal, M., S79

Manjunath, K. L., S107, S157

Mankolo, R. N., S95

Mann, H., S15

Mansfield, M. E., S135

Mansouri, S., S79

Mansouripour, S., S79

Manter, D. K., S163

Manzo-Sánchez, G., S79, S97

Marais, G., S121

Marano, M. R., S154

Marasas, W., S58

Marek, L. F., S13

Marek, S., S79
Marelli, J., S80

Margosan, D. A., S184

Markell, S. G., S45, S58

Marlow, G., S110

Marois, J., S59, S123, S148

Marques, A. S., S127

Marr, S., S39

Marra, R. E., S192

Marrero, G., S80, S101, S115

Marrone, P. G., S125

Marshall, D., S199

Martell, L., S24

Martillo, E. E., S80

Martin, B., S36

Martin, F. N., S12

Martin, J., S117

Martin, K. J., S80

Martin, M., S41, S42, S42

Martin, R. R., S2, S49, S106, S131, S184

Martin, S. B., S80

Martínez, B., S188, S190

Martinez, M. C., S149, S149

Martínez, Y., S190

Martinez-Zubiaur, Y., S189

Marupov, A., S80

Maruthachalam, K., S5, S65, S65, S81, S168

Mason, S., S76

Masri, S., S32

Matanguihan, G. J., S81

Matas-Baca, M. A., S109

Mateos-Hernandez, M., S25

Matheron, M., S81, S169, S184

Mathew, F. M., S45

Mathews, D. M., S123

Mathioni, S. M., S81, S204

Matsumoto, T., S63

Maughan, J., S134

Mavrodi, D. V., S174

Max Dow, J., S154

Maximova, S., S120

Mazourek, M., S91

Mazurek, S. A., S58

Mazzola, M., S105, S127, S150

McBeath, J. H., S160

McCafferty, H., S63

McCall, D., S26

McClean, A. E., S145

McCluskey, K., S179

McCollum, G., S11

McDonald, M., S45

McDonald, S. K., S26

McDonald, V., S32, S32, S33, S81

McDonnell, T., S63

McDowell, J., S164

McEvoy, P. B., S19

McFadden-Smith, W., S81

McFarland, K., S68, S193

McGhee, G. C., S82

McGranahan, G. H., S17

McGrath, J. M., S92

McGrath, M. J., S82

McGrath, M. T., S82, S144, S194, S194

McHale, L. K., S168

McInnes, B., S41, S42, S42

McInroy, J. A., S200

McKellar, M., S53

McKenzie, D., S70

McKinley, N., S41

McLaughlin, I. M., S82

McLeod, A., S127, S150

McManus, P. S., S47

McMillan, R. T., S19, S19

McMoran, D., S57, S183

McNeill, D. F., S199

McNellis, T., S120, S120
McPhee, K., S69

McPherson, B. A., S92

McRoberts, N., S174, S174

McSpadden Gardener, B. B., S10

McWilliams, M., S61

Medrano, E. G., S82

Meentemeyer, R., S163

Mehl, H., S82, S141

Meinhardt, L. W., S40

Meinhardt, S., S2

Meisenbach, T., S176

Meissner, H., S34, S70

Mekuria, T. A., S49, S83

Melander, C., S108

Melanson, R. A., S83, S114

Melcher, U. K., S110

Melero-Vara, J. M., S118

Melis, R., S90

Mello, A. F., S83, S83

Melnick, R. L., S83, S83, S203, S204

Melouk, H., S17

Melton, T., S4

Melzer, M. J., S118, S125

Mendoza, J. R., S40

Meng, F., S57, S166

Meng, Q., S84

Meng, X., S84

Meng, Y., S167

Mengistu, T. M., S84

Menke, J., S84

Mentreddy, R. S., S95

Mercier, J., S44, S84

Mergoum, M., S2, S49

Merhvar, M., S15, S84

Merritt, P. M., S154

Mersha, Z., S85

Metheney, P., S147

Meyer, F. W., S195, S195

Meyer, M., S85, S85, S184

Meyer, S., S85, S148

Meyers, B. C., S68

Mgbechi-Ezeri, J. U., S3

Michailides, T., S6, S77, S85, S89, S145

Michelmore, R. W., S168

Mickler, C., S180

Mideros, S. X., S164

Miglino, R., S29, S85

Miklas, P., S86

Mila, A., S4, S4, S162

Milagre, H. M., S40

Milbrath, G., S116

Miles, T. D., S86, S86, S86

Millard, M., S64

Miller, G. L., S86, S199

Miller, J., S180

Miller, K., S119

Miller, S., S9, S9, S31, S71, S82, S145, S160

Milling, A., S169

Mills, D., S50

Mills-Lujan, K., S86

Milus, E. A., S123, S125, S159

Mimee, B., S11

Minerdi, D., S41

Minero-García, Y., S89

Minsavage, G. V., S59

Minzenmayer, R., S198

Mirkov, E., S140

Misaghi, I. J., S98, S123

Misra, M., S34

Mitchell, B., S199

Mitchell, F. L., S33

Mitchell, M. N., S87, S171

Mitchell, T., S4, S7, S17, S22, S55, S107

Mitchum, M., S108, S147

Mittal, S., S147

Miyao, G., S9

Miyazoe, M., S87

Mizubuti, E. S., S25

Mlikota Gabler, F., S184

Mmbaga, M. T., S87, S87, S114

Mock, R., S73, S144

Moffet, M. D., S57

Mohammadi, H., S8

Mohammadi, M., S87

Mohan, K., S43

Mollov, D., S87

Mondal, S. N., S88

Monroy-Barbosa, A., S88

Monteiro, A. C., S25

Montero-Astúa, M., S88, S95

Montes de Oca, N., S189

Montzka, S., S173

Moore, A., S85

Moore, G. G., S88

Moore, S. R., S199

Moorhead, D., S175

Moorman, G., S53, S54, S145, S192

Moral, J., S88, S88

Morales, N., S122

Moran, Y. M., S189

Moreno-Valenzuela, O. A., S89

Morgan, C., S125

Morgan, D. P., S77, S85, S89

Morgan, J., S12

Morid, B., S60

Morishita, D. W., S62

Morra, M., S148

Morris, A. F., S89

Morris, T. F., S193

Morton, J., S12

Mosavi, L., S42, S89

Moscou, M. J., S167

Mosquera, G., S167

Mostert, L., S127

Moulin, F., S169

Moulton, K., S72

Moya, E. A., S89

Moyer, C., S101

Moyer, M. M., S89

Mozafari, J., S42, S89

Mozhaeva, K., S98

Mrema, F. A., S114

Msikita, W., S90, S90

Mueller, D. S., S11

Mukankusi, C., S90

Mukherjee, M., S90

Mukherjee, P. K., S26

Mukherjee, S., S90, S194

Mullen, J., S120 
Naegele, R. P., S92

Nagao, M. A., S183

Nagel, A. K., S92

Nagle, A. M., S92

Nagy, P. D., S165

Naidu, R. A., S2, S3, S68, S83, S125

Naik, M. K., S88

Naito, S., S57

Nandakumar, R., S62

Narusaka, Y., S63

Narvaez, D. F., S148

Natarajan, A., S92

Natarajan, S. S., S68

Natwick, E. T., S142

Nava-Diaz, C., S110

Navarre, D., S20, S39

Neate, S., S18, S47, S49, S49, S166

Neher, O., S62

Neijndorff, N., S66

Neill, T. M., S136, S136

Neisweinder, J., S183

Nelson, B. D., S103

Nelson, M. E., S33, S75

Nepal, A., S92

Nester, S. E., S14

Nettleton, D., S147

Newcomb, M., S92

Newman, M., S93, S131

$\mathrm{Ng}, \mathrm{J} ., \mathrm{S} 153$

Ngugi, H., S162, S162

Nguyen, D. T., S24

Nguyen, H., S147

Niblack, T., S76, S84

Nicol, J., S41, S103, S103

Nie, Y., S74

Niederholzer, F. J., S126

Nierman, W., S42, S166

Nieto-Angel, D., S40, S93, S110

Nikolaeva, E. V., S93

Nikolaeva, O. V., S30

Nischwitz, C., S93, S198, S200

Nissen, L., S93

Nita, M., S31, S93, S94

Nix, S. S., S94

Njambere, E. N., S94

Njau, P., S14

Noling, J. W., S94, S173

Noll, L. W., S94

Nolte, P., S166

Norelli, J., S14, S191

Noshad, D., S94

Nouri, S., S95

Novy, R. G., S187

Nowak, R. S., S91

Nunez, J., S76, S95

Nunney, L., S95

Nutter, F. W., Jr., S18, S160, S174

Nyczepir, A. P., S95

Nydam, S. D., S103

Nyochembeng, L. M., S95

O’Brien, G. K., S148

O'Connell, S., S109

O'Keeffe, T. L., S99

O'Mara, J., S63, S105

Oblinger, B. W., S95

OBrian, G., S54

Ocamb, C., S42, S87

Ochiai, N., S96

Ochoa, O. E., S168

Ochoa-Corona, F. M., S96

Odenbach, K. J., S96

Odintsova, T., S175

Oerke, E. C., S53

Ohkura, M., S194
Ojiambo, P., S171, S171

Okubara, P. A., S115, S186

Olanya, M., S69, S96

Olarte, R., S83

Olatinwo, R. O., S96

Olaya, G., S32, S169, S171

Oliver, J. E., S96

Olivera Firpo, P. D., S97

Olsen, J. P., S97

Olsen, M. W., S107

Olson, B., S176

Olson, E., S111

Olson, H. A., S97

Olson, J., S105

Olson, S., S128

Olszewski, N., S76

Omarov, R. T., S79

Ona, I., S17, S19

Orozco-Santos, M., S79, S97, S97

Orshinsky, A. M., S97

Ortega-Beltran, A., S98

Ortega-Corona, A., S98

Osborne, L., S22, S12

Osman, F., S44

Osorio, J. A., S98

Osterbauer, N., S61, S61, S84, S116

Otrosina, W. J., S8

Oudemans, P. V., S98, S103

Owens, R., S98

Ownley, B., S72

Ozbek, B., S62

Ozdemir, F., S103

Pacheco-Sabido, H., S89

Padgett, G., S98

Padmanaban, A., S32

Pádua, M. A., S25

Pagano, M. R., S34, S34

Pagliaccia, D., S98

Palacio, J., S188

Palacios, J. R., S189

Palencia, E. R., S99

Palmateer, A., S19, S19, S102

Palmieri, M. L., S68

Palou, L., S133

Palumbo, J. D., S99

Pan, Q., S148

Pan, S., S23

Panella, L., S18

Pappu, H., S3, S7, S7, S29, S31, S60, S74, S85, S112, S117

Paret, M. L., S99

Park, B., S99

Park, J., S99

Park, K., S70

Park, S., S99, S144, S167, S203

Parke, J., S96, S100, S100, S175

Parker, P. E., S13, S13

Parker, S. R., S100, S145, S185, S187

Parkunan, V., S100

Parnell, S., S13

Parpaiola Baroni, J. C., S36

Pasche, J., S140

Pastor-Corrales, M. A., S100

Pataky, J., S85, S198

Patel, J. S., S2, S49, S101, S101

Patel, N., S12, S100

Patton, A. F., S37

Paul, C., S52

Paul, P., S67, S67, S72, S94 S96, S115, S161

Paulitz, T., S6, S103, S103, S115, S147, S180, S186

Pavek, M. J., S74
Pavlic, D., S121

Payne, A., S101, S121

Payne, G., S42, S54

Payton, M. E., S129

Paz, J., S7, S96

Paz, Z., S65

Pearce, M., S198

Peckham, G. D., S68, S101, S101

Peet, M. M., S109

Peever, T., S55, S101, S124

Pegues, M. D., S50, S50

Peiman Williams, M., S51

Pena, A., S36

Pena, J., S101, S102

Peng, Y., S146, S150

Percich, J. A., S12

Pereira, G. A., S40

Peres, N. A., S78, S101

Pérez Bernal, M., S189

Perez Martinez, J. M., S102, S127

Perez, C. A., S102

Pérez, E., S190

Pérez, G., S102

Pérez, M., S88, S189

Pérez, Y., S189, S190

Pérez-Gago, M., S133

Perez-Moreno, L., S45

Perna, N. T., S163

Perry, K. L., S83, S83

Perugini, L., S25

Peteira, B., S188, S189

Peterson, D., S147

Peterson, P. D., S80

Peterson, S., S116

Pethybridge, S., S174

Petrisko, J. E., S185

Petropoulos, L., S24

Pfender, P., S184

Pfender, W., S24, S174, S182, S185

Phillips, J. G., S14

Phillips, L. L., S80

Phipps, P., S55, S102

Pierce, J., S114

Pierson, E., S154

Pietersen, G., S157

Pilar Marquez Villavincencio, M., S167

Pineda, J. B., S190

Pinheiro, J. B., S25

Pinkerton, J. N., S35

Pizzirani-Kleiner, A. A., S106

Plale, B., S7

Ploetz, R., S102, S102, S127

Pokharel, R., S103

Polashock, J. J., S98, S103

Poleatewich, A. M., S159

Polek, M., S147

Poole, G., S103, S103

Popko, J. T., S194

Poplawsky, A. R., S61, S103

Popov, M. S., S28

Porchas, M., S81, S169, S184

Poromarto, S., S103

Portal, O., S188

Porter, B., S104

Porter, L., S69, S86, S104

Postman, J., S13, S64, S104

Postnikova, E., S104, S104, S205

Powell, C., S11

Powers, K. L., S6

Prakash, S., S94

Prathuangwong, S., S5, S104

Precheur, R., S82

Press, C., S14, S136

Presting, G. G., S115

Price, J. A., S105, S105

Principal, J., S190

Prithiviraj, B., S125

Probst, C., S158

Proffer, T. J., S71

Pryor, B. M., S23

Pscheidt, J., S175

$\mathrm{Pu}, \mathrm{H} ., \mathrm{S} 149$

$\mathrm{Pu}, \mathrm{X} ., \mathrm{S} 28$

Pumphrey, M. O., S111

Puri, K., S70

Purvis, M. A., S98

Pusey, P. L., S105

Putnam, M. L., S117

Putnicki, L. S., S105

Qandah, I., S105

Qi, R., S41

Qiao, H., S39, S55

Qiu, J., S74, S105

Qu, Z., S56, S61

Quecine, M. C., S106

Quello, K., S21, S106

Quesada-Ocampo, L. M., S106

Quesenberry, N. J., S17

Quiñones Pantoja, M., S189

Quiñones, M., S190

Quirin, E. A., S15

Quito, D., S106

Qunqing, W., S164

Qunqing, W., S167

Radionenko, M., S107

Radwan, O., S36, S106

Rahman, M., S107

Rahmatov, A. A., S80

Rakhshandehroo, F., S42, S43, S89

Ramadugu, C., S107

Ramirez, H., S42

Ramirez, M. E., S132

Ramírez, R., S188

Ramming, D. W., S184

Ramos, E., S188, S189, S190

Randall, J. J., S107

Randles, J. W., S5

Ranjith-Kumar, C., S134

Rao Uppalapati, S., S168

Rappaport, K., S75

Raruang, Y., S99

Rasmussen, J. B., S2

Rathburn, H. B., S33

Rauf, A., S125

Rauscher, G., S107, S185

Rayapati, N. A., S49

Razdan, V. K., S118

Reay-Jones, F. P., S26

Recknor, J., S147

Records, A., S177 
Reyes, Y. D., S190

Reynolds, G. J., S108

Rezaee, S., S10, S113

Rhakhshandehroo, F., S2

Rhodes, L. H., S71, S82

Richardson, B. A., S64, S65

Richardson, P. A., S54, S145

Rideout, S. L., S144

Ridout, C., S108

Riegel, D. G., S6

Riley, K., S180

Riley, T., S117

Rimelspach, J. W., S66

Rines, H. W., S1

Rioux, D., S193

Ristaino, J. B., S48

Ritchie, D. F., S108

Rivara, C. J., S109, S180

Rizzati, M. R., S133

Rizzo, C., S81, S204

Rizzo, D. M., S35, S163

Rk, S., S109

Robayo-Camacho, E., S109

Roberts, D. P., S175, S203

Roberts, J. A., S109, S195

Roberts, P. D., S55, S56, S131, S171

Robertson, A., S11, S18, S124

Robertson, C. L., S91

Robertson, N. L., S109, S185

Robl, D., S117

Robles-González, M. M., S97

Robles-Hernández, L., S45, S109

Robles-Yerena, L., S110

Roca, M. M., S161

Rodrigues, F. A., S36

Rodrigues, J., S110

Rodriguez, D., S36

Rodriguez, L. M., S120

Rodríguez, P. A., S189

Roese, A. D., S28

Rogers, G., S41, S42

Rogers, S. A., S108

Rogers, S. M., S110, S110

Rojas, A., S64, S65, S130, S130

Rojas, M. R., S68

Rokas, A., S42

Rolshausen, P., S108

Ronaldo, A., S114

Rondon, S., S7

Roose, M. L., S107

Roossinck, M., S134

Rosenberger, D. A., S195, S195

Ross, D. S., S54, S145

Ross, R. E., S125

Rosskopf, E. N., S18, S54

Rotenberg, D., S110

Rothrock, C., S58, S132, S197

Rott, P. C., S110

Rougon, A., S108

Rouse, D. I., S43, S92

Rouse, M., S97, S111, S111

Roux, J., S121

Rowhani, A., S44, S44

Roy, A., S45, S111

Royer, M., S110

Rozyne, M., S191

Ruaro, L., S111

Rubin, A., S169

Ruden, B. E., S22

Ruden, K., S12

Rugh, A. L., S195, S195

Ruhl, G., S53, S143

Rupe, J. C., S132

Rush, C., S1, S52, S105, S105, S143, S140

Rush, M. C., S62

Russell, S. A., S201
Russo, N. L., S111

Ruzin, S. E., S73

Ryu, C., S168, S168, S203

Saad, A. T., S111

Saar, D., S3

Sabanadzovic, S., S112, S112, S112, S112, S112, S112, S113, S113, S124

Safaie, N., S79

Saffarian Abbas Zade, M., S113

Saffarian Abbas Zadeh, M., S113, S113

Saftner, R. A., S60

Sagaram, U. S., S48

Saghai Maroof, M. A., S50, S164

Saha, P., S134

Saini, M. K., S113

Sakhuja, A. G., S114

Salas, B., S18

Samac, D. A., S19

Sampangi, R. K., S43

Sampson, B. J., S121

Samuitiene, M., S3

Sánchez, M., S134

Sanderlin, R. S., S83, S114

Sanders, F. H., S114, S198, S199

Sanderson, J. P., S16

Sanogo, S., S77, S114, S114

Sansone, C., S198

Santamaria, L., S87, S114

Santos, M. O., S77

Saponari, M., S147

Sapp, P., S198

Saralamma, B., S201

Sarmiento, O., S53

Sauve, R. J., S87, S114

Savona, S., S61

Schaad, N., S104, S104, S115 S116, S157, S205

Schafer, J., S71

Schall, M. J., S195

Schardl, C. L., S126

Schell, M. A., S101

Scher, J., S117

Scherm, H., S23, S24, S33, S57, S128, S162

Schilder, A. C., S6, S86, S86, S86

Schisler, D., S67, S115

Schlatter, D., S115

Schlub, R. L., S85

Schmale, D. G., S204

Schmale, L., S172

Schmidt, F. J., S46

Schmidt, L. S., S17

Schnabel, G., S3, S3, S92

Schneider, A. T., S181

Schneider, K. L., S80, S115

Schneider, R., S20, S91, S115, S138, S197, S200, S201

Schneider, W., S104, S104, S205

Schnell, R., S102

Schoelz, J. E., S4

Scholthof, H., S3, S79, S140

Schomaker, C., S158

Schroeder, B. K., S29, S101, S 155

Schroeder, K., S103, S115, S147, S186

Schuenzel, E., S104, S115, S116, S157, S205

Schulthess, C. P., S193

Schultz, R., S61

Schwartau, K., S116

Schwartz, H. F., S176
Schweri, K., S116

Sciumbato, G., S72

Scocco, E. A., S116

Searle, D. W., S62

Sechler, A., S104, S104, S115,

S116, S157, S205

Sechler, K. E., S205

Sedegui, M., S116

Seebold, K. W., S59, S116, S200

Seem, R. C., S6, S89, S124

Sefah, K., S20

Segovia, V., S116

Segovia-Lerma, A., S45

Seifers, D., S117

Seijo, T. E., S101

Sekora, N., S117, S200

Semar, M., S37

Sengoda, V. G., S117

Seo, S., S70

Serdani, M., S117, S123

Serrano, D., S117

Serrano, E. S., S117

Serrano, Y., S118

Sether, D. M., S118, S125

Seybold, S., S133

Seymour, L., S33

Seyran, M., S200

Shaffer, B. T., S106

Shahjahan, A., S62

Shahnaz, E., S118

Shahraeen, N., S43

Shahriari, D., S2

Shamekova, M., S79

Shamoun, S. F., S10, S32

Shan, W., S164

Shang, Q., S75, S118, S118,

S140, S144, S150

Shannon, G., S72

Shao, A., S118

Sharma, N., S126

Sharma, R. C., S48

Sharma, S. K., S99

Sharma-Poudyal, D., S118

Shatters, R., S115, S116

Shaw, B. D., S90

Shaw, C., S99

Shaw, D. V., S65

Shcherbakova, L., S175

Shelman, T., S142

Shen, B., S151

Sheng, H., S119

Shennan, C., S18

Shepherd, L., S34, S34, S119

Sherman, D. J., S104, S205

Sherwood, E., S108

Sherwood, J., S178

Shew, D., S41

Shew, H., S39

Shi, A., S119, S119

Shim, W., S64, S78, S90, S119

Shin, J., S119

Shin, K., S70

Shiraishi, T., S63

Shishkoff, N., S205

Shock, C. C., S43

Sholberg, P. L., S119

Shrestha, S. M., S48

Shychuk, A. J., S20

Sierotzki, H., S169, S169, S169

Sierra, R., S40, S120

Sikora, E. J., S120

Sikora, R. A., S53

Sim, S. T., S44, S44

Simard, M., S193

Simko, I., S107

Simon, S. W., S131

Singh, B. L., S129

Singh, D. K., S120

Singh, P. K., S2, S49, S120

Singh, R., S25, S53, S120

Sinn, J. P., S120

Sinnott, Q., S64

Sisterson, M., S124, S170

Skantar, A. M., S85, S120

Skaria, M., S120

Slawinska, J., S53

Sleper, D., S72

Slininger, P. J., S67

Slinski, S. L., S121

Slippers, B., S12, S102, S102, S121

Sloan, J. M., S67

Smart, C. D., S46, S142

Smilanick, J. L., S184

Smilde, S., S156

Smiley, R. R., S103

Smiley, R. W., S121, S121, S146

Smith, A. L., S65

Smith, B. J., S121

Smith, D. L., S101, S121

Smith, D. R., S95

Smith, J., S102

Smith, K., S49, S102

Smith, L. J., S47

Sneller, C., S72, S96

Sniezko, R. A., S122, S122

Snook, M. E., S7, S44

Snyder, G., S176

Socha, C., S122

Soika, M. D., S129

Sokhandan Bashir, N., S42, S89, S195

Solano, F., S51

Solis, K., S83, S83

Song, E., S41

Song, Q., S25, S140

Songkumarn, P., S17

Sosnowski, M. R., S108

Soto-Arias, J. P., S122

Sotomayor, M., S189

Soule, M., S83, S86

South, D. B., S199

Souza, J. A., S133

Spaine, P. C., S8

Spakes Richter, B., S122

Sparks, A. H., S122

Speers, C., S143

Spiers, J., S72, S72

Spotts, R., S36, S123

Springer, J. C., S123

Spurgeon, D. W., S10

Spurlock, T. N., S123

Srivastava, P., S123 
Sthapit, J., S125

Stier, J. C., S66

Stiger, D., S178

Stipanovic, R. D., S168

Stockwell, V. O., S104, S105

Stoddard, C., S180

Stoddard, S., S9

Stodghill, P., S163

Stone, A. G., S87

Stone, A. L., S104, S205

Stouthamer, R., S95

Stover, E., S115, S116

Stoxen, S., S111

Strand, J., S182, S184

Strausbaugh, C. A., S30, S125

Strelkov, S. E., S21, S56

Strem, M. D., S204

Strine, J., S63

Strobel, D., S37

Stuart, J. D., S193

Sturgill, M. C., S129

Su, H., S125, S182, S186

Suárez-Capello, C., S83, S83

Subbarao, K. V., S4, S5, S65, S65, S81, S168

Subere, C. V., S125

Subramanian, S., S125

Sudarsana, P., S125

Sudarshana, M. R., S126

Sudini, H., S201

Sugawara, K., S126

Sugiyama, L., S63, S183

Sullivan, C., S14

Sumampong, G., S10, S32

Sumner, L. W., S132

Sumner, P., S196

Sun, G. Y., S71

Sun, J., S146

Sun, W., S126

Sundin, G. W., S66, S71, S82, S82

Sung, S. S., S8

Suomeng, D., S164

Sutton, W., S61, S61

Svircev, A., S119

Sweany, R., S27, S126

Sweets, L. E., S126

Sweigard, J. A., S81, S204

Swett, C., S126

Szabo, L. J., S111

Szankowski, I., S42

Taheri, H., S60

Taipe, A., S8

Talley, J., S139

Tally, A., S169, S180

Tan, W., S20

Tande, C., S105

Tang, W., S48

Tarnowski, T. L., S127

Tatineni, S., S127

Tavantzis, S. M., S166

Taylor, B., S31

Taylor, T. A., S127, S201

Tedford, E., S181

Teixeira, A. O., S127

Téliz-Ortiz, D., S110

Temple, T. N., S127, S186

Tewoldemedhin, Y., S127, S150

Thekke Veetil, T., S128

Thies, J. A., S29, S128

Thill, C. A., S64

Thomas, C., S24, S160, S171, S172, S174, S181, S181, S182, S182, S184, S185

Thomas, E., S166

Thomas, S., S128

Thomashow, L., S174

Thomma, B., S65

Thompson, A., S64
Thompson, D. C., S128

Tiburcio, R. A., S40

Tifft, K., S9

Tilley, M., S94

Tillman, B. L., S197

Tisserat, N., S13, S37, S69, S128, S133

Tiuli, L., S164, S167

Tiwari, K., S198

Toda, T., S57, S63, S166

Todey, D. P., S22

Toews, M., S199

Tojo, M., S133

Tolin, S. A., S176

Tomaso-Peterson, M., S21, S128

Tomimatsu, G., S175

Tooley, P. W., S205, S205

Toth, I., S27

Townley, M. A., S135

Toyoda, K., S63

Trail, F., S20

Trammell, L., S147

Trapero, A., S134

Trapero-Casas, A., S88, S88

Traquair, J. A., S24, S129

Travadon, R., S9

Travis, J. W., S159, S193

Tredway, L. P., S86, S127,

S129, S129, S199, S201

Trent, M. A., S129

Trick, H. N., S116

Trigiano, R., S72, S72

Tripathy, S., S164, S167

Trivedi, P., S129

Troisi, M., S129

Trouillas, F., S108, S186

Truco, M.-J., S168

Trujillo, C. A., S130

Tsai, C., S130

Tsai, T., S130

Tsai, W., S21

Tseng, H., S130

Tsui, C. K., S51

Tumbalam, P., S64, S65, S130, S130

Turechek, W. W., S131, S139, S171

Turgeon, B. G., S149

Turini, T., S9, S131

Turnbull, G. D., S21, S56

Turoop, L., S131

Tuttle, A., S191

Tweddell, R. J., S11, S193

Tyler, B. M., S164, S167

Tzanetakis, I., S112, S131, S131, S142

Tzeng, K., S56, S73

Ueki, S., S165

Ueng, P., S132

Ullman, D. E., S9

Upchurch, R. G., S132

Uppala, S., S132, S201

Uppalapati, S., S132, S132

Upper, C. D., S92

Urbez-Torres, J., S186

Uribe, P., S12

Urrea, K. E., S132

Utley, C., S37, S128, S133

Uyemoto, J. K., S126

Uzuhashi, S., S133

Vahling, C. M., S133

Vaiciunas, J., S103

Vaillancourt, L., S20

Vaillant, D., S189, S190

Vaira, A., S73

Valdebanito-Sanhueza, R. M., S133
Valencia-Chamorro, S. A., S133

Valent, B., S167

Vallad, G., S133, S133, S168

Valladares, C., S40

Valverde, R., S113, S134

Van den Bosch, F, S13

Van der Walt, F., S121

van der Wolf, J. M., S27, S134

van der Zouwen, P. S., S134

Van Dijk, K., S130

van Ettekoven, C., S155

Van Etten, H. D., S140

Van Santen, E., S200

van Schadewijk, A. R., S29, S85

Van Sluys, M., S69

van Veen, J. A., S27

van Vliet, A., S66, S66

van Vuuren, S. P., S157

van Wyk, P., S58

Vanblaere, T., S42

Vandemark, G., S94

Vardi, Y., S134

Varga, A., S32

Vargas, A., S134

Variar, M., S19

vas Santen, E., S117

Vasquez, S., S134

Vázquez-Jiménez, J. L., S97, S97

Velarde-Felix, S., S28

Velasquez, N., S24

Velázquez-Monreal, J. J., S97

Venkataprasanna, T., S45

Venter, S., S27

Venugopal, S., S20, S79

Vera Cruz, C., S17, S19

Vera, D. I., S83

Verhoeven, K., S66

Veronese, P., S4, S65, S165

Viator, R. P., S46

Vicente, M., S134

Vico, I., S60, S135

Vidalakis, G., S147

Vidal-Martinez, V. A., S98

Vidaver, A., S43, S52, S104

Vierling, R., S119, S119

Vigil, M., S18

Vilgalys, R., S166

Villamil, A., S37

Villani, S. M., S25, S135

Vincelli, P., S33, S200

Vining, K. J., S135, S135

Vinyard, B. T., S85

Viteri, D. M. S135

Vitoreli, A. M., S51, S135

Vittal, R., S77, S136

Vojnov, A. A., S154

von Bodman, S., S154

Wadl, P., S72

Wager-Page, S., S177

Walcott, R., S59, S116, S137, S198

Walgenbach, P., S136

Walker, A., S74

Walker, D. R., S123

Walker, N. R., S121

Walkinshaw, C. H., S136, S201

Wallace, P. K., S136, S136

Wallis, C., S136

Wallis, K., S123

Walter, M., S121

Walters, E., S62

Walters, T., S43, S117

Wan, A., S137

Wang, C., S90, S138

Wang, D., S137

Wang, G., S17, S30, S107

Wang, H., S74, S75

Wang, J., S74, S108

Wang, K., S168

Wang, L., S118, S148

Wang, M., S72, S78, S137, S138

Wang, N., S48, S129

Wang, X., S23, S56, S137, S138, S140

Wang, Y., S61, S140, S150, S164

Wang, Z., S137

Wangdi, T., S168

Wanner, L. A., S138

Wanyera, R., S14

Ward, N., S201, S138

Warner, K. D., S175

Warnke, S. E., S3

Warren, J. G., S138

Wasala, L., S139

Wasonga, C., S100

Watanabe, K., S139

Watson, A., S193

Wayadande, A., S139, S170

We, R., S131

Weaver, B., S64

Weaver, M. A., S1, S58, S139

Webb, S., S139, S171

Webber, J., S35

Weber, E., S44

Webster, C. G., S131, S139

Webster, R. K., S20

Wegulo, S. N., S53

Wegulo, S. W., S127

Wegulo, S., S94, S139

Wei, B., S140

Wei, G., S138

Wei, H., S140, S140

Wei, L., S140

Wei, W., S139, S143

Wei, Y., S75, S118, S140, S150

Weiland, J., S31, S140

Welham, S. J., S13

Weller, D. M., S174

Wells, L. W., S50

Wen, A., S140

Wen, F., S140

Wen, R., S50

Weng, Z., S141

Weselowski, B., S1

Wessel-Beaver, L., S110

Westermann, D. T., S181

Westphal, A., S141

Wharton, P., S7, S64

Wheeler, T. A., S201

White, D., S141

White, F. F., S5

White, G., S140 
Wingfield, B., S12, S58, S102, S121

Wingfield, M., S12, S58, S102, S102, S102, S121

Wintermantel, W. M., S142, S142

Wise, K., S143

Wise, R. P., S167

Wisniewski, M. E., S14

Wittwer, D. T., S52

Woloshuk, C., S42, S152

Wolpert, T. J., S167

Wood, D. L., S92

Woodward, J. E., S143, S201

Workneh, F., S52, S105, S143

Wortman, J., S42

Woudt, B., S66, S143

Wraight, S. P., S16

Wrather, A., S72

Wright, A. F., S143

Wright, D., S59, S123, S148

Wright, G., S88

Wu, W., S139, S143

Wu, X., S147

Wunsch, M. J., S143

Wyenandt, C. A., S144

Xaviér, C. J., S88

Xia, Y., S39, S79

Xiang, H., S144

Xiang, M., S144

Xiang, P., S144

Xiao, C., S63, S75, S150, S187

Xiaobo, Z., S164

Xiaoli, W., S164, S167

Xiaoli, Y., S164, S167
Xie, Y., S99, S144, S144, S202

Xing, L., S141

Xinle, W., S164, S167

Xiong, Z., S140, S141

Xu, D., S144

Xu, H., S145

Xu, J., S28, S29, S146, S146, S154

Xu, L., S137

Xu, W., S167

Xu, X., S145, S148

Xu, Z., S54, S145

Xue, B., S145

Xue, Q., S140, S146

Xue, W., S118

Yaghmour, M. A., S145

Yakabe, L. E., S145, S187

Yan, G., S146

Yan, H., S121, S121

Yan, K., S118

Yang, B., S5

Yang, H., S150

Yang, J., S146, S146

Yang, K., S150

Yang, M., S146

Yang, S., S146

Yang, T., S146

Yao, Y., S164, S167

Yasari, E., S35

Yasuhiro, I., S132, S132

Ye, D., S150

Yeater, K., S17

Yeckel, G. J., S147

Yi, M., S167

Yin, C., S29, S147
Yin, H., S147

Yin, J., S57

Yin, J., S84

Yokomi, R. K., S147

Yoshioka, H., S63

Young, C., S147, S152

Young, H., S36, S91, S148

Young, R. F., S30

Young, S., S65

Yousef, L. F., S148

Yu, H., S23

Yu, J., S42, S72, S144, S149

Yu, K., S39, S79

Yu, Y., S148

Yuan, B., S148

Yuan, X., S95

Yuen, G., S147

Zablotowicz, R. M., S1, S139

Zabowski, D., S71

Zachritz, J. W., S194

Zale, J., S72

Zamani, A., S75

Zamanizadeh, H., S60

Zambon, J. L., S111

Zanzot, J. W., S148

Zasada, I., S35, S43, S148

Zeglen, S., S51

Zeng, Q., S65

Zeng, W., S148

Zeng, X., S148

Zerbini, F. M., S190

Zerbini, P. A., S190

Zhai, C., S148

Zhang, G., S150

Zhang, H., S61, S138
Zhang, L., S140, S144, S149

Zhang, N., S149

Zhang, P., S156

Zhang, R., S71

Zhang, S., S38, S149, S149

Zhang, W., S136, S146

Zhang, X., S118, S149, S165

Zhang, Y., S149, S150

Zhang, Z. W., S22

Zhao, H., S150, S150

Zhao, J., S137

Zhao, W., S150

Zhao, X., S75, S140, S146, $\mathrm{S} 150, \mathrm{~S} 150$

Zhao, Y., S67, S70, S132, S137, S139, S143, S155

Zheng, Y., S151

Zhengguang, Z., S164

Zhong, S., S49, S70

Zhou, G., S144

Zhou, J., S164

Zhou, L., S11, S73, S74, S151, S157, S164

Zhou, T., S138

Zhou, X., S63, S151, S205

Zhu, J., S63, S104

Zhu, S., S77, S79

Zhu, X., S48, S75, S151

Zid, M., S41

Ziems, A., S43, S105, S127

Zimmermann, B. H., S39

Zipfel, C., S108

Zitter, S. M., S91

Zitter, T. A., S91, S91

Zlesak, D., S87

Zwonitzer, J., S10 